\title{
JMCP Article Index by Subject Category — with Hyperlinks
}

\author{
July/August 1995 through November/December 2010
}

Editors' note: This index categorizes the entire 16-year archive of JMCP articles, editorials, commentaries, letters, and supplements to inform about what is already known in these areas of managed care research. Each citation listed in this index is hyperlinked to the source article on JMCP web pages; this Article Index complements the word-search capability at "Search JMCP" available at www.amcp.org.

\section{ACS, Atrial Fibrillation, CHD, and CHF}

- Association between the use of 4 recommended drug categories and patient perceptions of health status following an ACS event. 2009;15(7):533-42

- Atrial fibrillation and managed care: current approaches and future directions for long-term therapy. [supplement] 2009;15(6-b):S1-S30.

- Pharmacy benefit spending poised to increase for antithrombotic drug therapy - prasugrel versus clopidogrel. [editorial] 2009;15(5):414-16.

- Review of prasugrel for the secondary prevention of atherothrombosis. 2009; 15(5):383-95.

- Critical review of prasugrel for formulary decision makers. 2009;15(4):335-43

- Meta-analysis to assess the quality of warfarin control in atrial fibrillation patients in the United States. 2009;15(3):244-52.

- HEDIS, beta-blockers, and what more can be done to improve secondary prevention in ACS. [editorial] 2008;14(3):316-17.

- Suboptimal utilization of secondary drug prevention in acute coronary syndrome: measurement issues and managed care opportunities. [commentary] 2008;14(3):312-15.

- Use of secondary prevention drug therapy in patients with acute coronary syndrome after hospital discharge. 2008;14(3):271-80.

- Managing patients with chronic angina: emerging therapeutic options for improving clinical efficacy and outcomes. [supplement] 2006;12(8):S1-S24.

- Value for money in disease management of acute coronary syndrome-the price of aspirin to reduce the costs of ACS. [editorial] 2005;11(4):355-57.

- Total first-year costs of acute coronary syndrome in a managed care setting. 2005;11(4):300-06.

- Congestive heart failure: a disease management approach in longterm care patients. 1999;5(6):516-20.

- Direct medical costs of unstable angina pectoris in a defined population. 1999;5(1):39-44.

- Managing congestive heart failure in a Medicare risk population. 1999;5(1):14-16.

- Changing practices in home inodilator infusion therapy for advanced congestive heart failure. 1998;4(1):73-77.

\section{Adherence, Compliance, and Persistence}

- Comparing medication persistence across 6 chronic therapy classes to identify the greatest need for improvement. 2009;15(9):728-40

- Nonadherence, clinical inertia, or therapeutic inertia? [editorial] 2009;15(6):690-95.

- Retrospective observational assessment of statin adherence among subjects patronizing different types of community pharmacies in Canada. 2009;15(6):476-84.

- Unfilled prescriptions of Medicare beneficiaries: prevalence, reasons, and types of medicines prescribed. 2008;14(6):553-60.

- Prevalence of unclaimed prescriptions at military pharmacies. 2008;14(6):541-52.

- Compliance, adherence and persistency: an examination of clinical intervention and insurance design strategies to improve outcomes. [supplement] 2008;14(6, S-d):S1-S17.

- The unhidden cost of noncompliance. [supplement] 2008;14(6, S-b):S1-S29.
- Informing patients about drug effects using positive suggestion. [letter] 2008;14(4):395-96.

- Improving medication adherence: the role of the health care delivery system and health care providers. [commentary] 2007;13(9):807-09.

- Relationship of the magnitude of member cost-share and medication persistence with newly initiated renin angiotensin system blockers. 2007;13(8):664-76.

- Analysis of factors associated with statin adherence in a hierarchical model considering physician, pharmacy, patient, and prescription characteristics. 2007;13(6):487-96.

- Patient adherence with hypertension medication. [letter] 2004;10(1):90-91.

- Measuring adherence to antihypertensive drug therapy. [letter] 2004;10(1):88-89.

- Hypertension, prescription drug copayments and drug therapy adherence. 2003;9(5):454-56.

- Patient adherence with amlodipine, lisinopril, or valsartan therapy in a usual-care setting. 2003;9(5):424-29.

- Measuring adherence and persistence in drug therapy. 2002;8(3):204-46.

- Patient adherence with HMG reductase inhibitor therapy among users of two types of prescription services. 2002;8(3):186-91.

- Adherence, compliance, and persistence in drug therapy. 2002;8(3):177-78.

- A team approach to address antiretroviral therapy adherence barriers in a managed care organization. 2001;7(3):214-18.

- The Michigan pharmacists association patient persistency project. 2001;7(1):50-55.

- Evaluating medication adherence: which measure is right for your program? 2000;6(6):499-504.

- Unclaimed prescriptions requisitioned through provider order entry. 1999;5(6):498-502.

- Predicting adherence to prescription medication purchase among HMO enrollees with diabetes. 1999;5(4):336-41.

- Analyzing variations in medication compliance related to individual drug, drug class, and prescribing physician. 1999;5(1):47-51.

- A study on the characteristics of prescription transmittal processes and the effect of a patient prescription reminder system on patient compliance. 1998;4(2):174-78.

- "Abandoned prescriptions": a quantitative assessment of their cause. 1995;1(3):193-99.

\section{Adverse Drug Events}

- Adverse drug events in the elderly: an ongoing problem. [commentary] 2009;15(7):568-71.

- Preventable drug-related morbidity (PDRM). [editorial] 2003;9(2):178

- Indicators of preventable drug-related morbidity in older adults. 2 Use within a managed care organization. 2003;9(2):134-41.

- Medical errors, adverse medical events, and PDRM. 2002;8(5):400.

- Preventable drug-related morbidity indicators in the U.S. and U.K. 2002;8(5):372-77.

- Preventable drug-related morbidity in older adults. 1. Indicator development. 2002;8(5):365-71.

- Evaluation of resources used to treat adverse events of selective serotonin reuptake inhibitor use. 2001;7(5):402-06. 
- Adverse drug events: a plea for reporting and new rules to ease the burden. 1998;4(4):364.

\section{Airway Disease and Allergic Rhinitis}

- Strategies for improving asthma outcomes: a case-based review of successes and pitfalls. [supplement] 2010;16(1-c):S1-S20.

- Omalizumab and other new drug therapies occupy a small space in asthma disease management. [editorial] 2009;15(3):289-93.

- Omalizumab has a place in therapy for asthma disease management. [commentary] 2009;15(3):284-88.

- Economic burden in direct costs of concomitant chronic obstructive pulmonary disease and asthma in Medicare Advantage population. 2008;14(2):176-85.

- Review of the NAEPP 2007 expert panel report (EPR-3) on asthma diagnosis and treatment guidelines. 2008;14(1):41-49.

- Quality of drug treatment of childhood persistent asthma in Maryland Medicaid recipients in transition from managed fee for service to managed capitation. 2007;13(4):310-18.

- Effects on resource utilization of adding salmeterol in combination or separately to inhaled corticosteroids, 2007;13(1):21-27.

- From asthma severity to asthma control: identification of new guidelines. [supplement] 2006;12(9):S1-S14.

- The diminishing role of montelukast in asthma therapy. [letter] 2006;12(6):487-89.

- Health care utilization determined from administrative claims analysis for patients who received inhaled corticosteroids with either montelukast or salmeterol. [letter] 2006;12(6):486-87.

- An algorithm for the identification of undiagnosed COPD cases using administrative claims data. 2006;12(6):458-65.

- More evolution of the evidence in asthma disease managementSMART versus GOAL clinical trials debate the cost-benefit of LABA while the value of leukotriene modifiers, particularly montelukast, is uncertain. [editorial] 2006;12(4):343-46.

- PP-ICONS-another tool to help interpret asthma utilization studies. [editorial] 2006;12(4):341-42.

- Administrative claims analysis of asthma-related health care utilization for patients who received inhaled corticosteroids with either montelukast or salmeterol as combination therapy. 2006;12(4):310-21.

- Measuring value in the treatment of symptoms of allergic rhinitis with nasal steroids. [editorial] 2006;12(2):168-69.

- Asthma disease management-evidence-based medicine must be dynamic. [editorial] 2006;12(1):80-82.

- Analysis of the effectiveness and cost benefit of leukotriene modifiers in adults with asthma in the Ohio Medicaid population. 2006;12(1):33-42.

- Selectivity and specificity are the keys to cost-effective use of omalizumab for allergic asthma. [editorial] 2005;11(9):774-76.

- Evaluation of omalizumab from a health plan perspective. 2005;11(9):735-45.

- Antibiotic use in children who have asthma: results of retrospective database analysis. 2005;11(8):657-62.

- New concepts to improve health outcomes for patients with chronic obstructive pulmonary disease. [supplement] 2005;11(6, S-a):S1-S22.

- Contemporary issues in the care of patients with chronic obstructive pulmonary disease. [supplement] 2005;11(5, S-a):S1-S16.

- COPD — whose burden, how large, and what to do about it? [editorial] 2005;11(1):90-93.

- The impact of chronic obstructive pulmonary disease on long-term disability costs. 2005;11(1):25-32.

- Overview of chronic obstructive pulmonary disease: new approaches to patient management in managed care systems. [supplement] 2004;10(4, S-a):S1-S25.

- Allergic rhinitis, asthma, and rhinosinusitis: diseases of the integrated airway. 2004;10(4):310-17.
- Alternate managed care approaches to disease management of allergic rhinitis. [editorial] 2004;10(3):267.

- Identification of allergic disease among users of antihistamines. 2004;10(3):234-38.

- Pediatric asthma: improving management to reduce cost of care. 2004;10(2):130-41.

- Evaluation of the utilization patterns of leukotriene modifiers in a large managed care health plan. 2004;10(2):115-21.

- Enhancing value-based decision-making: allergic rhinitis. [supplement] 2004;10(1, S-a):S1-S17.

- Unmet needs in the treatment of allergic asthma: potential role of novel biologic therapies. 2003;9(6):534-43.

- Exploring new frontiers in asthma management for optimal therapeutic and economic outcomes. [supplement] 2003;9(5):S1-S25.

- Optimizing clinical and economic outcomes in asthma management: individualizing drug therapy to address dual components of asthma. [supplement] 2002;8(5):S1-S25.

- Impacts of a PBM-based disease management program on asthma medication use. 2001;7(6):460-67.

- Costs and utilization patterns associated with persistent asthma: a comparison of Texas Medicaid patients with and without continuous inhaled corticosteroid treatment. 2001;7(6):452-59.

- Evaluating asthma medication use before and after an acute asthmarelated event. 2001;7(4):303-08.

- An investigation of allergic rhinitis, asthma, and medication use in a privately insured population. 2001;7(4):287-91.

- A claims data analysis of patient acquisition of drug therapies for the treatment of asthma. 1999;5(4):342-46.

- Evaluating health-related quality of life in three disease management areas: asthma, diabetes, and hypertension. 1996;2(4):408-13.

- Asthma disease management: integration of DUR, case management, and performance indicators. 1996;2(1):59.

\section{ALS (Amyotrophic Lateral Sclerosis)}

- Treatment of patients with ALS: implications for the managed care pharmacist. 1996;2(6):599-604.

\section{Alzheimer's Disease}

- Cholinesterase inhibitor utilization patterns: just because it can be counted does not mean it counts. [commentary] 2008;14(5):462-64.

- Comparison of cholinesterase inhibitor utilization patterns and associated health care costs in Alzheimer's disease. 2008;14(5):451-61.

- Does persistence with drugs for Alzheimer's disease matter? [editorial] 2005;11(3):260-62.

- Drug persistency patterns for patients treated with rivastigmine or donepezil in usual care settings. 2005;11(3):231-39.

\section{Arthritis and Joint Pain}

- Formulary review of 2 new biologic agents: tocilizumab for rheumatoid arthritis and ustekinumab for plaque psoriasis. 2010;16(6):402-16.

- Viscosupplementation: managed care issues for osteoarthritis of the knee. [supplement] 2007;13(4):S1-S23.

- Total knee replacement delayed with hylan G-F 20 use in patients with grade IV osteoarthritis. 2007;13(2):113-21.

- Modernization versus limitation: cross-firing the impact of the AHRQ Effective Health Care Program on access to biologic therapies. [supplement] 2007;13(1):S1-S24.

- Review of eight pharmacoeconomic studies of the value of biologic DMARDs (adalimumab, etanercept, and infliximab) in the management of rheumatoid arthritis. 2006;12(7):555-69.

- Relative value of the NSAIDs, including COX-2 inhibitors and meloxicam. [editorial] 2006;12(3):265-67. 
- COX-2 inhibitors: little or no GI protection, increased risk of cardiovascular events, high cost, and other class-less effects. [editorial] 2005;11(7):590-93.

- Gastrointestinal bleeding rates among managed care patients newly started on COX-2 inhibitors or nonselective NSAIDs. 2005;11(7):550-58.

- Frequency, predictors, and economic impact of upward dose adjustment of infliximab in managed care patients with rheumatoid arthritis. 2005;11(5):383-93.

- Cost-effective use of COX-2 drugs and NSAIDs. [editorial] 2002;8(4):295-96.

- Relationship of clinical factors to the use of COX-2 selective NSAIDs within an arthritis population in a large HMO. 2002;8(4):252-58.

- Economic considerations in the management of arthritis. 1999;5(6):476-78, 481-82, 484.

- New options in the treatment of arthritis. 1999;5(5):443-48.

- Pharmacoeconomics of NSAIDs: beyond bleeds. 1997;3(4):425-30.

\section{Atopic Dermatitis}

- Atopic march to a dead end or does the theory really have legs? [editorial] 2007;13(9):810-11.

- Economic burden of atopic manifestations in patients with atopic dermatitis—analysis of administrative claims. 2007;13(9):778-89.

- Administrative claims analysis of utilization and costs of care in health plan members with atopic dermatitis who had prior use of a topical corticosteroid and who initiate therapy with pimecrolimus or tacrolimus. 2007;13(4):349-59.

- Prevalence and costs of atopic dermatitis. 2002;8(5):404.

- The effect of atopic dermatitis on total burden of illness and quality of life on adults and children in a large managed care organization. 2002;8(5):333-42.

\section{Attention-Deficit/Hyperactivity Disorder (ADHD)}

- Changes and challenges: managing ADHD in a fast-pace world. [supplement] 2007;13(9, S-b):S1-S16.

- ADD or ADHD or what exactly?-GIGO part II and other lessons in research with administrative claims. [editorial] 2007;13(7):617-19.

- Continuity in methylphenidate treatment of adults with attentiondeficit/hyperactivity disorder. 2007;13(7):570-77.

- Health care costs of adults treated for attention-deficit/hyperactivity disorder who received alternative drug therapies. 2007;13(7):561-69.

- Factors associated with initiation with atomoxetine versus stimulants in the treatment of adults with ADHD: retrospective analysis of administrative claims data. 2006;12(3):230-38.

- ADHD: disease or social misfit? [editorial] 2005;11(4):342-43.

- Disease management of ADHD and measures of compliance. [editorial] 2004;10(2):166-67.

- Stimulant treatment patterns and compliance in children and adults with newly treated attention-deficit/hyperactivity disorder. 2004;10(2):122-29.

- Physician perceptions of the use of medications for attention deficit hyperactivity disorder. 2003;9(5):416-23.

\section{Behavioral Health}

- Issues and trends in behavioral health and managed care. 2000;6(1):11, 12, 15-16.

\section{Benign Prostatic Hyperplasia}

- Value for money in disease management of benign prostatic hyperplasia. [editorial] 2004;10(5):456.

- Cost-effectiveness of tamsulosin, doxazosin, and terazosin in the treatment of benign prostatic hyperplasia. 2004;10(5):412-22.

\section{Biotechnology}

- Biotechnology and managed care. 2000;6(5):410-14.

- Biotechnology as a pharmacy specialty. 1998;4(5):465, 468-70.

\section{Cancer and Chemotherapy}

- Payer costs for inpatient treatment of pathologic fracture, surgery to bone, and spinal cord compression among patients with multiple myeloma or bone metastasis secondary to prostate or breast cancer. 2010;16(9):693-702.

- Budgetary impact of treatment with adjuvant imatinib for 1 year following surgical resection of kit-positive localized gastrointestinal stromal tumors. 2010;16(7):482-91.

- Neutropenia-related costs in patients treated with firstline chemotherapy for advanced non-small cell lung cancer. 2009;15(8):669-82.

- Sensitivity of administrative claims to identify incident cases of lung cancer: a comparison of 3 health plans. 2009;15(8):659-68.

- Budget impact analysis of ixabepilone use according to FDAapproved labeling in treatment-resistant metastatic breast cancer. 2009;15(6):467-75.

- Use of erythropoiesis-stimulating agents among chemotherapy patients with hemoglobin exceeding 12 grams per deciliter. 2008; 14(9):858-69.

- Analysis of costs associated with administration of intravenous single-drug therapies in metastatic breast cancer in a U.S. population. 2008;14(9):844-57.

- Recent advances in the understanding and treatment of multiple myeloma. [supplement] 2008;14(7-S):S1-S29.

- Optimizing outcomes through pharmaceutical advances in the treatment of chronic myeloid leukemia. [supplement] 2007;13(8, S-a):S1-S20.

- Observational study of the prevalence of febrile neutropenia in patients who received filgrastim or pegfilgrastim associated with 3-4 week chemotherapy regimens in community oncology practices. 2007;13(4):337-48.

- Pharmacy benefit spending on oral chemotherapy drugs. 2006;12(7):570-77.

- Evaluation of erlotinib in advanced non-small cell lung cancer: impact on the budget of a U.S. health insurance plan. 2006;12(6):472-78.

- Cost-minimization analysis of once-weekly versus thrice-weekly epoetin alfa for chemotherapy-related anemia. 2004;10(6):531-37.

- Targeted therapies in the treatment of colorectal cancer: what managed care needs to know. [supplement] 2004;10(5, S-b):S1-S17.

- Oncology drugs and managed care. 1998;4(4):374-75, 378, 380.

\section{Capitation and Risk-Financing Methods}

- Paying for outcomes: innovative coverage and reimbursement schemes for pharmaceuticals. [commentary] 2009;15(8):683-87.

- Contractual arrangements between HMOs and medical groups to manage drug costs. [editorial] 2003;9(6):572.

- Financial risk relationships and adoption of management strategies in physician groups for self-administered injectable drugs. 2003;9(6):523-33.

- Demographics and the cost of pharmaceuticals in a private thirdparty prescription program. 2000;6(5):395-402, 407-09.

- Challenges to methods used in studying capitation reimbursement. [letter] 2000;6(1):8.

- The impact of pharmaceutical capitation to primary medical groups on the health care expenditures of Medicare HMO enrollees. 1999;5(5):414-19.

- Managing pharmacy risk in physician groups. 1999;5(5):382-84. 


\section{Chronic Constipation}

- Optimal treatment of chronic constipation in managed care: review and roundtable discussion. [supplement] 2008;14(9-a):S1-S17.

\section{Chronic Kidney Disease (CKD)}

- Clinical and economic outcomes in Medicare beneficiaries with stage 3 or stage 4 kidney disease and anemia: the role of intravenous iron therapy. 2010;16(8):605-15.

- No TREATment with darbepoetin dosed to 13 gm per dL in type 2 diabetes with pre-dialysis chronic kidney disease-safety warnings with erythropoiesis-stimulating agents, [editorial] 2009;15(9):759-65.

- Empirical methods to calculate an erythropoiesis-stimulating agent dose conversion ratio in nondialyzed patients with chronic kidney disease. 2009;15(9):741-50.

- Direct all-cause health care costs associated with chronic kidney disease in patients with diabetes and hypertension: a managed care perspective. 2009;15(4):312-22

- Managed care to Medicare: sharing the burden of chronic kidney disease. [supplement] 2007;13(9, S-d):S1-S24.

- Outcomes of secondary hyperparathyroidism in chronic kidney disease and the direct costs of treatment. 2007;13(5):397-411.

- Causes and consequences of chronic kidney disease: implications for managed health care. [supplement] 2007;13(3):S1-S9.

- Assessment of time and practice resources required to provide weekly or monthly erythropoiesis-stimulating protein therapy to chronic kidney disease patients in the physician office setting. 2006;12(9):714-25.

- Examination of resource use and clinical interventions associated with chronic kidney disease in a managed care population. 2003;9(3):248-55

- Resource use and patient care associated with chronic kidney disease in a managed care setting. 2003;9(3):238-47.

\section{Clinical Pharmacy-Patient Consultation}

- Insulin pump therapy training and management: an opportunity for community pharmacists. [commentary] 2008;14(8):790-94.

- Pharmacists should assume a larger role in overcoming the racial/ ethnic barriers to breast cancer screening. [letter] 2006;12(5):406-07.

- Factors affecting pharmacist consultation services in a university health insurance plan. 2002;8(1):32-40.

- Providing patient-focused care within a managed care and pharmaceutical care environment: a person/situation interactionist model for community practitioners. 2000;6(3):233-39.

- Counseling: where does the profession stand? 1998;4(1):78.

\section{Clinical Pharmacy-Payment for Services}

\section{and Medication Therapy Management}

- Outcomes of a rheumatoid arthritis disease therapy management program focusing on medication adherence. 2010;16(8):593-604.

- Medication therapy management: 10 years of experience in a large integrated health care system. 2010;16(3):185-95.

- Medication therapy management favors large pharmacy chains and creates potential conflicts of interest. [commentary] 2009; 15(6):495-500.

- Examination of MTM opportunities in pediatric behavioral health. [letter] 2009;15(5):420-22.

- Analysis of pharmacist-provided medication therapy management (MTM) services in community pharmacies over 7 years. 2009; 15(1):18-31.

- PSTAC survey in 2006 was instrumental in obtaining permanent (category 1) CPT codes for MTM services performed by pharmacists. [letter] 2008;14(1):86-87.
- Disease management, pay-for-performance, and clinical pharmacist interventions in diabetes care. [editorial] 2003;9(6):574.

- Outcomes-based pharmacist reimbursement: reimbursing pharmacists for cognitive services. 2002;8(5):383-91.

- Reimbursement for pharmacy cognitive services: pharmacists' assessment. 1999;5(5):420-24.

- Cost-benefit analysis of pharmaceutical care in a Medicaid population—from a budgetary perspective. 1998;4(3):303-08.

- Reimbursement for pharmacy cognitive services: insurance company assessment. 1997;3(1):46-48, 50-51.

- Mississippi Medicaid waiver breaks new ground for pharmacists. 1996;2(6):564, 566.

- Community-based pharmacy: partnering with managed care to provide value-added services. 1996;2(5):483, 487-88.

\section{Clinical Pharmacy Interventions-}

Quality, Service, and Cost Outcomes

(see also Medication Therapy Management)

- Results from a mailed promotion of medication reviews among Department of Defense beneficiaries receiving 10 or more chronic medications. 2010;16(8):578-92.

- Descriptive analysis of a clinical pharmacy intervention to improve the appropriate use of stress ulcer prophylaxis in a hospital infectious disease ward. 2010;16(2):114-21.

- Pharmacist recommendations to improve the quality of diabetes care: a randomized controlled trial. 2010;16(2):104-13.

- Opportunities and considerations for pharmacist intervention in the management of the chronic hepatitis $C$ patient. [letter] 2009;15(5):417-19.

- Pharmacist intervention in treatment of patients with genotype 1 chronic hepatitis C. 2009;15(2):147-50.

- A prospective trial of a clinical pharmacy intervention in a primary care practice in a capitated payment system. 2008;14(9):831-43.

- Actual versus projected cost avoidance for clinical pharmacy specialist-initiated medication conversions in a primary care setting in an integrated health system. 2008;14(2):155-63.

- The Hickory Project builds on the Asheville Project—an example of community-based diabetes care management. [letter] 2007;13(6):531-33.

- Medication therapy management versus drug regimen review. [commentary] 2007;13(1):68-69.

- Adherence to clinical practice guidelines for 7 chronic conditions in long-term-care patients who received pharmacist disease management services versus traditional drug regimen review. 2007;13(1):28-36

- Experience with a clinical decision support system in community pharmacies to recommend narrow-spectrum antimicrobials, nonantimicrobial prescriptions, and OTC products to decrease broad-spectrum antimicrobial use. 2006;12(5):390-97.

- Impact of a clinical pharmacy consult service on guideline adherence and management of gabapentin for neuropathic pain. 2006;12(1):61-69.

- Assessment of patient satisfaction with telephone and mail interventions provided by a clinical pharmacy cardiac risk reduction service. 2005;11(5):403-09.

- The PRICE clinic for low-income elderly: a managed care model for implementing pharmacist-directed services. 2005;11(4):333-41.

- Assessment of the effects of a community pharmacy women's health education program on management of menopause survey scores. 2004;10(5):442-48.

- Clinical pharmacist intervention in a primary care medical group reduces financial losses. [editorial] 2004;10(4):355.

- Impact on drug costs and utilization of a clinical pharmacist in a multisite primary care medical group. 2004;10(4):345-54 
- Clinical pharmacist interventions to bridge the quality chasm and methods necessary to hold quality improvement gains. [editorial] 2004;10(2):167-68.

- Cost analysis of a managed care decentralized outpatient pharmacy anticoagulation service. 2004;10(2):159-65.

- Assessment of clinical pharmacist management of lipid-lowering therapy in a primary care setting. 2003;9(3):269-73.

- A pharmacist-based screening program of octogenarians starting new medications. 2003;9(1):13-18.

- Crossing the quality chasm-pharmacist prescribing, nontraditional interventions, and outcomes-based pharmacist reimbursement (OBPR). 2002;8(5):403-04.

- Determining the value of pharmacy services-the search for rigorous research designs. 2002;8(2):152-53.

- Quality and cost outcomes of clinical pharmacist interventions in a capitated senior drug benefit plan. 2002;8(2):124-31.

- Community pharmacists and diabetes health care. 2002;8(1):56-57.

- Factors affecting pharmacist consultation services in a university health insurance plan. 2002;8(1):55-56.

- Effects of a community pharmacist-based diabetes patient management program on intermediate clinical outcome measures. 2002;8(1):48-53.

- Collaborating with community pharmacists to improve the quality of diabetes care in an IPA-model HMO. 2001;7(4):292-96.

- Implementation and evaluation of a pharmacist-managed diabetes service. 2000;6(6):488-93.

- Impact of a diabetes disease management clinic on the total glycosylated hemoglobin of patients with type 2 diabetes mellitus. 1999;5(6):511-15.

- Using patient expectations and satisfaction data to design a new pharmacy service model in a primary care clinic. 1997;3(5):531-40.

- AIDS enters new era with pharmacists on the front lines. 1997;3(4):391-92, 395-96.

- Outcomes management: the why, what, and how of data collection. 1997;3(3):345-51

\section{Clinical Pharmacy Quality Improvement- Patient Safety and Prevention of ADEs}

- Results of a safety initiative for patients on concomitant amiodarone and simvastatin therapy in a Veterans Affairs medical center. 2010;16(7):472-81.

- Development of pictographs depicting medication use instructions for low-literacy medical clinic ambulatory patients. 2010;16(5):337-45.

- An exploratory comparison of medication lists at hospital admission with administrative database records. 2009;15(9):751-58.

- Sources and types of discrepancies between electronic medical records and actual outpatient medication use. 2008;14(7):626-31.

- Integration of medical and pharmacy claims to better protect patient safety—a long road yet to travel. 2007;13(5):429-30.

- Telithromycin: the perils of hasty adoption and persistence of offlabel prescribing. 2007;13(5):420-25.

- Preventing medication errors and adverse drug events. 2003;9(1):92-93.

- The role of managed care pharmacy in reducing medication errors. 2003;9(1):62-65.

- Quality improvement, risk management, and patient education: tools to reduce medication error. 2001;7(2):156-63.

- Adverse drug reaction tracking and management in an integrated health care system. 1997;3(6):644-47, 650.
Clinical Practice Guidelines (CPGs), Evidence-Based Practice and Quality Improvement

- Development and delivery of a quality improvement program to reduce antipsychotic polytherapy. 2010;16(6):393-401.

- British Petroleum and pay-for-performance in primary care. [letter] 2010;16(6):424.

- Clinical quality indicators and provider financial incentives: does money matter? [editorial] 2010;16(5):360-66.

- Intervention to increase the proportion of acute myocardial infarction or coronary artery bypass graft patients receiving an order for aspirin at hospital discharge. 2010;16(5):329-36.

- Adding diagnosis codes to prescriptions: lessons learned from a quality improvement project. [letter] 2009;15(6):508-10.

- Provider prescribing of 4 antiretroviral agents after implementation of drug use guidelines in the Department of Veterans Affairs. 2009;15(4):323-34.

- Adherence to international antimicrobial prophylaxis guidelines in cardiac surgery: a Jordanian study demonstrates need for quality improvement. 2009;15(3):262-71

- Call for letters regarding disclosure of potential conflicts of interest in the managed care literature-Too much, too little, or just about right? [editorial] 2009;15(2):166.

- What should be done about bias and misconduct in clinical trials? [editorial] 2009;15(2):154-60.

- Accuracy in pharmacoeconomic literature review: lessons learned from the Navajo Code Talkers. [editorial] 2008;14(9):886-91.

- Rethinking the "whodunnit" approach to assessing the quality of health care research-a call to focus on the evidence in evidencebased practice. [editorial] 2008;14(7):661-74.

- 2008: a tipping point for disease management? [commentary] 2008;14(7):643-49.

- Looking for the outcomes we love in all the wrong places: the questionable value of biomarkers and investments in chronic care disease management interventions. 2008;14(6):563-70.

- Improving chronic care management: connecting health information technology and quality measurements. [supplement] 2008;14(2, S):S1-S25.

- Evaluation of the relationship between a chronic disease care management program and California pay-for-performance diabetes care cholesterol measures in one medical group. 2007;13(7):578-88

- Comprehensive coronary artery disease care in a safety-net hospital: results of Get With the Guidelines quality improvement initiative. 2007;13(4):319-25.

- Rhythm versus safety in amiodarone therapy. [editorial] 2006;12(8):687-89.

- Liver and thyroid monitoring in ambulatory patients prescribed amiodarone in 10 HMOs. 2006;12(8):656-64.

- Adherence to the NASPE guideline for amiodarone monitoring at a medical university. 2006;12(3):254-59.

- Chasing quality - clinical practice guidelines and HEDIS measures of asthma and depression therapy management. [editorial] 2006;12(1):78-80.

- The shift towards evidence-based medicine-the role of communitybased guidelines. [supplement] 2005;11(4):S1-S19.

- Evidence-based medicine: beware of results from randomized controlled trials and research with administrative claims data. [editorial] 2005;11(2):172.

- Management of NSAID-induced upper GI disorders using AMCP's Framework for Quality Drug Therapy. [supplement] 2005;11(2):S1-S19.

- Who needs another clinical practice guideline? [editorial] 2004;10(5):456-58.

- Framework for pharmacy services quality improvement-a bridge to cross the quality chasm. 2004;10(1):60-78. 
- Consensus panel, national guidelines, and other potentially misleading terms. [editorial] 2003;9(6):575.

- Evidence-based medicine, practice guidelines, and disease management. [editorial] 2003;9(6):573.

- Information technology to cross the quality chasm. 2002;8(5):401-02

- Crossing the quality chasm-incremental change through clinical practice guidelines (CPGs). [editorial] 2002;8(5):400-01.

- Quality improvement opportunities in health care-making it easy to do it right. 2002;8(5):394-99.

- Actual prescribing versus guidelines. 2002;8(4):297-98

- Relationship of clinical factors to the use of COX-2 selective NSAIDs within an arthritis population in a large HMO. 2002;8(4):252-58.

- A prescription for change: bridges to cross the "quality chasm." 2001;7(4):309-14

- Designing a framework for pharmacy practice: a look at consumer reactions and expectations. 2001;7(3):193-200.

- An assessment of the effectiveness of a nonsteroidal antiinflammatory drugs algorithm in an integrated health care system. 2001;7(2):149-55.

- Quality measures: looking in all the wrong places. 2001;7(2):88

- Medical and medication errors: a partial summary of reports by the Institute of Medicine and the quality interagency coordination task force. 2001;7(1):62-68.

- The case for pharmacy report cards. 1999;5(3):176, 179-80, 182.

- Response-oriented patient evaluation survey (ROPES): an administrator's tool for identifying opportunities for service quality improvement. 1998;4(3):311-20.

- Developing disease state management in the United Kingdom: an obviously American conjecture finds export opportunities abroad. 1998;4(3):275-76, 279-83, 287.

- Managing drug therapy decisions: pay me now or pay me later. 1998;4(3):242, 245

- Performance reporting for managed care prescription programs 1998;4(2):160-66.

- Do we measure up in reducing morbidity and mortality? 1997;3(6):651-52, 654-55, 658 .

- Medical outcomes: creating new opportunities for pharmacy. 1997;3(3):289-92

- How to evaluate disease state management programs. 1997;3(3):270, 273-74, 277-78.

- Managed care and the quest for quality measures. 1997;3(3):255, 258-89.

- Documenting indicators of pharmaceutical care in rural community pharmacies. 1996;2(6):659-66.

- Innovations in quality improvement: managed care leads the way. 1996;2(1):20, 22, 24, 27-28.

- Successful CQI-based programs in a group-model managed care setting. 1995;1(2):134, 137.

- Disease state management. 1995;1(2):128-33.

- Quality assessment and quality assurance of pharmacy services. 1995;1(1):40-51.

- Pharmaceutical care: needed now more than ever. 1995;1(1):21-22, 25.

\section{Collaboration-Pharmacists and Others}

- Prevalence and types of disease management programs in community pharmacies in California. 2005;11(6):505-12.

- Improving antimicrobial use: longitudinal assessment of an antimicrobial team including a clinical pharmacist.

2004;10(2):152-58.

- Rear window: actuaries and pharmacists-toward a new competency. 2001;7(3):233-37.

- Physician attitudes toward pharmacist-run anticoagulation clinics in Department of Defense Health Services Region 5. 1998;4(4):413-19.
- Physician groups embrace pharmacists: collaborations that work. 1997:3(5):526-28, 530

- Blood pressure outcomes in a pharmacist-and-nurse managed hypertension clinic: a team approach. 1997;3(3):307-12

- Pharmacy practice in the long-term care environment. 1997;3(2):189-94

\section{Collaboration-Pharmacy Education}

- A unique partnership: the Arkansas College of Pharmacy and the Arkansas PRO. 2002;8(1):12, 14.

- Oregon State University partners with Medicaid and a managed care organization. 2001;7(3):185-86.

- The University of Colorado School of Pharmacy and the University of Colorado Health Plan forge a PBM partnership. 1998;4(5):478, 480.

- Rutgers opens door to managed care. 1997;3(6):717-18.

\section{Collaborative Practice and Pharmacists as Prescribers}

- Medication therapy management and collaborative drug therapy management. [letter] 2010;16(1):67-69.

- Collaborative pharmacy practice: an idea whose time has come. 1999;5(6):487-88, 491

\section{Computerized Prescription Order Entry, Electronic} Prescribing, and Health Information Technology

- Lessons learned from randomized trials and recent experiences with health information technology: promising interventions meet realworld patient care. [editorial] 2010;16(9):718-28.

- Standardization is necessary in the methods to assess the value of electronic prescribing systems. [letter] 2005;11(7):594-95.

- Why e-prescribe and the future of transforming data into information. [editorial] 2005;11(5):418-19.

- Effects of electronic prescribing on formulary compliance and generic drug utilization in the ambulatory care setting: a retrospective analysis of administrative claims data. 2005;11(5):410-15.

- Clinical, service, and cost outcomes of computerized prescription order entry. [editorial] 2005;11(4):353-55.

- 12-month drug cost savings related to the use of an electronic prescribing system with integrated decision support in primary care. 2005;11(4):322-32.

- Understanding decision support systems. 2002;8(2):96-101

- Extent of electronic prescribing implementation as perceived by MCO pharmacy managers. 2002;8(1):41-47.

- Electronic prescribing in ambulatory care: a market primer and implications for managed care pharmacy. 2001;7(2):115-20.

- Connecting physicians to pharmacies — and patients. 1998;4(5):473-74, 477.

- Electronic prescribing: the next revolution in pharmacy? 1998:4(1):35-36, 39

\section{Crohn's Disease}

- Are gastroenterologists less tolerant of treatment risks than patients? Benefit-risk preferences in Crohn's disease management. 2010;16(8):616-28.

\section{Database Analyses of Drug Utilization (see also Research Methods)}

- Categorizing patients from medical claims data-the influence of GIGO. [letter] 2004;10(6):559-60.

- Oral isotretinoin: an analysis of its utilization in a managed care organization. 2002;8(4):272-77.

- Claims data and drawing appropriate conclusions. 2002;8(2):152. 
- Cost and utilization patterns of fentanyl transdermal system and oxycodone hydrochloride controlled-release in a California Medicaid population. 2002;8(2):132-40.

- Administrative databases and outcomes assessment: an overview of issues and potential utility. 1999;5(3):215-22.

- Basics of managed care claims processing: from claims payment to outcomes management. 1995;1(3):200-05.

\section{Depression and Bipolar Disorder}

- Prevalence and humanistic impact of potential misdiagnosis of bipolar disorder among patients with major depressive disorder in a commercially insured population. 2008;14(7):632-42.

- Switching antidepressant drug therapy helps some patients some of the time - what TORDIA, STAR*D, and observational research have taught us about treatment-resistant depression. [editorial] 2008;14(5):468-73

- "Depression" - Just what I thought. [commentary] 2008;14(6):561-62.

- Pharmacy and medical costs associated with switching between venlafaxine and SSRI antidepressant therapy for the treatment of major depressive disorder. 2008;14(5):426-41.

- Shrinking health care disparities in women: the depression dilemma. [supplement] 2007;13(9, S-a):S1-S36.

- The cost-effectiveness of lamotrigine in the maintenance treatment of adults with bipolar disorder. 2006;12(4):322-30.

- Utilization and drug cost outcomes of a step-therapy edit for generic antidepressants in an HMO in an integrated health system. 2006;12(4):294-302.

- Referral bias and other perspectives on the HEDIS measuring stick for quality of care in depression treatment. 2006;12(1):76-77.

- Higher costs and therapeutic factors associated with adherence to NCQA HEDIS antidepressant medication management measures: analysis of administrative claims. 2006;12(1):43-54.

- Comparison of mental health resources used by patients with bipolar disorder treated with risperidone, olanzapine, or quetiapine. 2005;11(3):220-30.

- Depression in corporate America: an integrated care approach to increase productivity and improve outcomes. [supplement] 2005;11(3):S1-S23.

- Evidence-based medicine: are SSRIs more effective than placebo and what length of therapy is enough? [editorial] 2005;11(2):172-76.

- Relationship of total health care charges to selective serotonin reuptake inhibitor utilization patterns including the length of antidepressant therapy-results from a managed care administrative claims database. 2005;11(2):145-50.

- Depression: new perspectives, understandings, and treatments. [supplement] 2004;10(2, S-a):S1-S25.

- Depression in managed care: costs of selective serotonin reuptake inhibitors. 2001;7(2):142-48.

- Documentation of indicators for antidepressant treatment and response in an HMO primary care population. 2000;6(6):494-98.

- Utilization patterns of antidepressant medications in a patient population served by a primary care medical group. 1999;5(3):243-49.

- SSRI-to-SSRI switching and associated dosing characteristics. 1999;5(2):138-43.

- The treatment of depression with newer antidepressants: pharmacology and efficacy versus clinical effectiveness. 1999;5(1):57-62.

\section{Diabetes (see also Clinical Pharmacy Interventions-} Quality, Service, and Cost Outcomes)

- Relationship between glycemic control and diabetes-related hospital costs in patients with type 1 or type 2 diabetes mellitus. 2010;16(4):264-75.

- Call for comparative effectiveness research: lowering Alc with sitagliptin, saxagliptin, or cinnamon. [editorial] 2009;15(8):696-700.

- Drug use evaluation of sitagliptin dosing by pharmacist versus nonpharmacist clinicians in an internal medicine department of a private physician-owned multispecialty clinic. 2009;15(6):563-67.

- The payer's dilemma: recognizing the uncertainty of clinical and economic evidence at product launch. [letter and editors' response] 2009;15(2):167-70.

- Diabetes drug therapy-first do no harm. [editorial] 2008;14(7):658-60.

- The benefits and risks of new therapies for type 2 diabetes. [commentary] 2008;14(7):655-57.

- New agents in the management of type 2 diabetes: do they provide an opportunity for a shift in the treatment paradigm? [commentary] 2008;14(7):650-54.

- Rosiglitazone and pioglitazone utilization from January 2007 through May 2008 associated with five risk-warning events. 2008;14(6):523-31.

- Managing type 2 diabetes: going beyond glycemic control. [supplement] 2008;14(5, S-b):S1-S19.

- The impact of diabetes and associated cardiometabolic risk factors on members: strategies for optimizing outcomes. [supplement] 2008;14(1, S-c):S1-S16.

- Managed care perspective on three new agents for type 2 diabetes. 2008;14(4):363-80.

- The changing landscape of type 2 diabetes: the role of incretin-based therapies in managed care outcomes. [supplement] 2007;13(9, S-c):S1-S20.

- Type 2 diabetes and cardiovascular disease: reducing the risk. [supplement] 2007;13(2, S-a):S1-S17.

- Bridging the gap between pharmacoeconomics and the real-world practice of managed care pharmacy. [commentary] 2007;13(1):66-67.

- Application of economic analyses in U.S. managed care formulary decisions: a private payer's experience. 2006;12(9):726-35.

- What evidence supports guidelines for the use of ACE inhibitors and ARBs in diabetes? [editorial] 2006;12(8):690-91.

- Physician conformity and patient adherence to ACE inhibitors and ARBs in patients with diabetes, with and without renal disease and hypertension, in a Medicaid managed care organization. 2006;12(8):649-55.

- Total and component health care costs in a non-Medicare HMO population of patients with and without type 2 diabetes and with and without macrovascular disease. 2006;12(7):548-54.

- What are incretins, and how will they influence the management of type 2 diabetes? [supplement] 2006;12(7, S-a):S1-S16.

- Relationship of oral antihyperglycemic (sulfonylurea or metformin) medication adherence and hemoglobin Alc goal attainment for $\mathrm{HMO}$ patients enrolled in a diabetes disease management program. 2006;12(6):466-71.

- Blood pressure goal attainment according to JNC 7 guidelines and utilization of antihypertensive drug therapy in MCO patients with type 1 or type 2 diabetes. 2006;12(4):303-09.

- What is the future of thiazolidinediones (TZDs) after market introduction of inhaled insulin? [editorial] 2006;12(2):169-72.

- Economic impact of antidiabetic medications and glycemic control on managed care organizations: a review of the literature. 2006;12(2):130-42.

- Utilization and costs for compliant patients initiating therapy with pioglitazone or rosiglitazone versus insulin in a Medicaid fee-forservice population. 2006;12(2):121-29. 
- Evaluating the relationship between diabetes treatment and health care costs-measuring the atom with a yardstick? [editorial] 2005;11(7):588-89.

- Relationship of glycemic control to total diabetes-related costs for managed care health plan members with type 2 diabetes. 2005;11(7):559-64.

- Incretin mimetics: promising new therapeutic options in the treatment of type 2 diabetes. [supplement] 2005;11(7):S1-S15.

- Emerging perspectives on type 2 diabetes. [supplement] 2005;11(6, S-b):S1-S30.

- Trends in the management of type 2 diabetes: an emerging role for insulin. [supplement] 2005;11(1, S-b):S1-S13.

- New concepts in diabetes: how multihormonal regulation can improve glycemic control. [supplement] 2004;10(6, S-b):S1-S13.

- Markov modeling analysis of health and economic outcomes of therapy with valsartan versus amlodipine in patients with type 2 diabetes and microalbuminuria. 2004;10(1):26-32.

- Longitudinal assessment of a diabetes care management system in an integrated health network. 2003;9(6):552-58.

- Analysis of cost and utilization of health care services before and after initiation of insulin therapy in patients with type 2 diabetes mellitus. 2003;9(4):309-16.

- Real-world research in diabetes care and protocols for patient privacy. 2003;9(3):275-76.

- Misadventures in insulin therapy: are your members at risk? [supplement] 2003;9(3):S1-S13.

- Evaluating medication use for continuous quality improvement in diabetes care. 2002;8(5):378-82.

- Importance of blood glucose monitoring to achieve short- and longterm glycemic control. 1999;5(6):543-47.

- The cost of managing diabetes mellitus: focus on the oral pharmacologic management of type 2 diabetes. 1999;5(2):113-20.

- Use of glycosylated hemoglobin testing among patients with diabetes mellitus. 1997;3(6):691-96.

- Diabetic nephropathy prevention and the role of managed care pharmacists. 1997;3(6):682-87.

- Evaluating health-related quality of life in three disease management areas: asthma, diabetes, and hypertension. 1996;2(4):408-13.

- Saving vision: an intervention for HMOs. 1996;2(2):178, 180.

\section{Direct-to-Consumer Advertising (DTCA)}

\section{(see also Drug Promotion and Advertising)}

- United States, the last venue for direct-to-consumer advertising, props up the erectile dysfunction market. [editorial]

2005;11(2):176-78

- Direct-to-patient advertising (DTPA) and direct-to-consumer advertising (DTCA) of prescription drugs. 2002;8(6):521.

- Promotion of prescription drugs to consumers: case study results. 2002;8(6):512-18.

- Responding to direct-to-consumer advertising. 2000;6(3):201-02.

- Direct-to-consumer advertising provides challenge to managed care. 1999;5(2):101-03, 106.

- The patient as a partner in prescribing: direct-to-consumer advertising. 1998;4(1):15-16, 18-19.

\section{Disease Pathology and Prevention}

- Prophylaxis of cervical cancer and related cervical disease: a review of the cost-effectiveness of vaccination against oncogenic HPV types. 2010;16(3):217-30.

- Economic evaluation of childhood 7-valent pneumococcal conjugate vaccination in Korea. 2010;16(1):32-45.

- The value of preventive medicine: a look at vaccine management. [supplement] 2007;13(7, S-b):S1-S23.

- Influenza: a practical review. 2000;6(3):247-48.
Dose Optimization-Dose Consolidation and Tablet Splitting

- Tablet splitting: much ado about nothing? [commentary] 2009;15(3):272-74.

- Analysis of drug content and weight uniformity for half-tablets of 6 commonly split medications. 2009;15(3):253-61.

- Initial results of the use of prescription order change forms to achieve dose form optimization (consolidation and tablet splitting) of SSRI antidepressants in a state Medicaid program. 2006;12(6):449-56.

- Dose consolidation can be an efficient intervention. [letter and author response] 2004;10(6):564-66.

- Randomized controlled trial of a dose consolidation program. 2004;10(5):396-403.

- Dose-optimization intervention yields significant drug cost savings. 2002;8(2):146-51.

- Dose optimization: an opportunity for pharmacy administrative services. 2002;8(2):81.

\section{Drug Benefit Management-Benchmarks and Measures}

- Principles and practical applications of benchmarking. [supplement] 2005;11(1, S-a):S1-S23.

- Other DACON observations-community pharmacists do not intentionally transmit incorrect claim information-but caution is warranted in days supply calculations. [letter] 2004;10(2):174-75.

- Need for greater scrutiny of days supply values in DACON calculations. [letter] 2004;10(2):172-73.

- Managed care pharmacy-weighing clinical, service, and cost outcomes. [editorial] 2004;10(1):84-85.

- Finding the truth about health care cost drivers-price versus utilization factors. 2003;9(3):274-75.

- Searching for drug benefit benchmarks_cost per day of therapy. 2002;8(1):54-55.

- The use of economic models in managed care pharmacy decisions. 1998;4(1):42-50.

\section{Drug Benefit Management-Benefit Design}

- Is "value-based" value wasted? Examining value-based insurance designs through the lens of cost-effectiveness. [commentary] 2010;16(2):130-33.

- Still looking for health outcomes in all the wrong places? Misinterpreted observational evidence, medication adherence promotion, and value-based insurance design. [editorial] 2009;15(6):501-07.

- What pharmacy benefit designers need to know about perception and reality: never forget the elephant in the pharmacy. [editorial] 2008;14(4):387-94.

- The editors respond regarding the shortcomings in reported research on value-based insurance design. [letter] 2008;14(3):326-28.

- Confronting hysteria: a reply to Fairman and Curtiss. [letter] 2008;14(3):324-26.

- Making the world safe for evidence-based policy: let's slay the biases in research on value-based insurance design. [editorial] 2008;14(2):198-204.

- The future of prescription drug cost-sharing: real progress or dropped opportunity? [editorial] 2008;14(1):70-82.

- Effect on drug utilization and expenditures of a cost-share change from copayment to coinsurance. 2007;13(9):765-77.

- Factors associated with choice of pharmacy setting among DoD health care beneficiaries aged 65 years or older. 2007;13(8):677-86.

- The elephant in the pharmacy: patient choice is the big challenge that no one talks about in affordability of prescription drugs. [editorial] 2007;13(7):620-22. 
- Comparison of mail-order with community pharmacy in plan sponsor cost and member cost in two large pharmacy benefit plans. 2007;13(2):122-34.

- Relationship of the use and costs of physician office visits and prescription drugs to travel distance and increases in member cost share. 2006;12(8):665-76

- Heartburn in consumer-directed health care and the cost outcomes of therapeutic maximum allowable cost. [editorial] 2006;12(5):402-05

- Pharmacy management methods in Canada, including lower-cost therapy for heartburn. 2006;12(5):398-401.

- Cost reduction strategies used by elderly patients with chronic obstructive pulmonary disease to cope with a generic-only pharmacy benefit. 2006;12(5):377-82

- Effect of a therapeutic maximum allowable cost (MAC) program on the cost and utilization of proton pump inhibitors in an employersponsored drug plan in Canada. 2006;12(5):371-76.

- Mail-service pharmacy savings: a conclusion in search of evidence. 2006;12(2):164-67.

- The estimated impact of drug importation, mandatory mail service, and Medicaid fee reduction on community pharmacies in Michigan. 2006;12(2):157-63.

- A 30-month evaluation of the effects on cost and utilization of proton pump inhibitors from adding omeprazole OTC to drug benefit coverage in a state employee health plan. 2006;12(1):25-32.

- The role of pharmaceuticals in reducing cardiometabolic risk: rethinking pharmacy benefit design to reduce the burden on the health care system. [supplement] 2006;12(1):S1-S16.

- OTC omeprazole for your heartburn-enormous value-for-money opportunity. [editorial] 2004;10(5):458-59.

- Effects on the cost and utilization of proton pump inhibitors from adding over-the-counter omeprazole to drug benefit coverage in a state employee health plan. 2004;10(5):449-55.

- Does member cost-sharing pose a threat to desirable patient outcomes? 2004;10(3):256.

- Effects of an increase in prescription copayment on utilization of low-sedating antihistamines and nasal steroids. 2004;10(3):226-33.

- 3-tier drug benefit designs based on sound drug formulary principles will maximize favorable outcomes. [editorial] 2004;10(1):83-84.

- Benefit maximums versus drug benefit needs for Medicare beneficiaries. 2002;8(5):402-03.

- Prescription use behavior among Medicare beneficiaries with capped prescription benefits. 2002;8(5):360-64.

- Effects of Medicare+Choice annual maximum dollar prescription drug benefits. 2002;8(3):178.

- A cost analysis of four benefit strategies for managing a COX-2 inhibitor. 2001;7(3):224-27.

- Three-tier copay systems and consumer-centric care. 2000;6(5):351-53.

- Medicare-risk pharmacy benefit design: a new cost-effective approach to pharmacy management. 1997;3(1):103-04, 106.

\section{Drug Benefit Management-Efficiency and Patient Safety}

- Resistance to in-office dispensing of generic antibiotic samples. [commentary] 2009;15(1):62-65.

- Case study of the effects of office-based generic drug sampling on antibiotic drug costs and first-line antibiotic prescribing ratios. 2009;15(1):55-61.

- Rosiglitazone and pioglitazone utilization from January 2007 through May 2008 associated with five risk-warning events. 2008;14(6):523-31.

- Perspectives on the "generic cliff" - pushing and falling. [editorial] 2008;14(3):318-21.

- Market withdrawal of Vioxx: is it time to rethink the use of COX-2 inhibitors? [editorial] 2004;10(6):551-54.
- Guiding principles for effective electronic messaging. [letter] 2004:10(6):560-64.

- Weight uniformity of split tablets required by a Veterans Affairs policy. 2003;9(5):401-07.

- Mail-order prescriptions requiring clarification contact with the prescriber: prevalence, reasons, and implications. 2003;9(4):346-52.

- Tablet splitting to improve the value-for-money equation in cholesterol management. [editorial] 2002;8(6):519.

- Effects of a tablet-splitting program in patients taking HMG-CoA reductase inhibitors: analysis of clinical effects, patient satisfaction, compliance, and cost avoidance. 2002;8(6):453-58.

- A model to estimate drug plan cost savings from a trial prescription program. 2001;7(5):391-401.

- A model for comparing unnecessary costs associated with various prescription fill-quantity policies: illustration using VA data. 2001;7(5):386-90.

- The impact of a telephone care pharmacy program on health care resource utilization. 2000;6(3):217-21.

- Pharmacy cost reduction imperative at United HealthCare. 1999;5(1):19-20.

- The evolution of best-in-class pharmacy management techniques. 1998;4(4):366-67, 370, 372-73.

- Practice guidelines, physician groups, and drug formularies. 1997;3(5):489-92.

- Maximizing generic substitution in managed care. 1998;(4)6:557-60, 562-63.

- Pharmacy benefit administration options. 1996;2(3):272-78.

\section{Drug Benefit Management- Employee Benefits and Coverage (see also Drug Benefit Management-Benefit Design)}

- Member satisfaction related to self-reported cost share and difficulty in obtaining prescription drugs in a university pharmacy benefit plan. 2007;13(2):135-41.

- Shifting the focus from cost to value: key stakeholder perspectives. [supplement] 2006;12(6, S-b):S1-S26.

- Evaluation of product switching after a state Medicaid program began covering loratadine OTC 1 year after market availability. 2006;12(2):108-20.

- Prescription-equivalent over-the-counter drugs for allergy, heartburn, and cholesterol reduction. [editorial] 2005;11(1):94-96.

- Older adults' drug benefit beliefs: a focus group study. 2005;11(1):77-85.

- Managed care market perspectives on the over-the-counter availability of statins. 2004;10(6):543-50.

- Anticipating the future: how the emergence of innovative biologic agents impacts benefit design, utilization, and provider relations. [supplement] 2004;10(3, S-a):S1-S20.

- New generic and OTC drugs provide opportunities for drug benefit managers. 2002;8(6):520.

- Analysis of the movement of prescription drugs to over-the-counter status. 2002;8(6):499-508.

- Employee benefits consulting: an essential role for pharmacy. 2001;7(4):268-71.

- Employer-sponsored health care services. 2001;7(3):189-92.

- Pharmacy benefit managers and unique customer segments: large employers. 2000;6(5):342-44, 346.

- The history, philosophy, and principles of pharmacy benefits. 1999;5(6):525-31.

- Quality-of-life drugs: framing the issue. 1999;5(3):185, 189-90.

- Successful disease management programs for health and welfare fund union groups. 1998;4(3):269-70, 272.

- Carve outs and pharmacy: fashion or fad? 1996;2(4):352, 354-55, 359. 


\section{Drug Benefit Management-Generic Dispensing Ratio}

- Prescription drug costs and the generic dispensing ratio. 2010;16(7):502-06

- Addition of generic medication vouchers to a pharmacist academic detailing program: effects on the generic dispensing ratio in a physician-hospital organization. 2010;16(6):384-92.

- Effects of a physician office generic drug sampling system on generic dispensing ratios and drug costs in a large managed care organization. 2007;13(5):412-19.

\section{Drug Benefit Management-Patient Satisfaction,}

\section{Benefit Knowledge, and Consumer Behavior}

- Evaluation of health plan member use of an online prescription drug price comparison tool. 2010;16(9):680-92.

- Willingness to pay for sensory attributes of intranasal corticosteroids among patients with allergic rhinitis. 2006;12(2):143-51.

- Consumer understanding and satisfaction associated with a 3-tier prescription drug benefit. 2005;11(6):480-92.

- Unraveling the effects of tier-copayment drug benefit designs. 2003;9(2):177-78.

- Effects of a 3-tier pharmacy benefit design on the prescription purchasing behavior of individuals with chronic disease. 2003;9(2):123-33

- Measuring outcomes of 3-tier copay drug benefit plans. 2002;8(6):522.

- Impact of multi-tiered pharmacy benefits on attitudes of plan members with chronic disease states. 2002;8(6):477-91.

- Consumer preferences for types of cost containment in prescription drug programs. 2002;8(3):192-98.

- Drugs, PPOs, tiered cost-share for beneficiaries, and consumer preferences. 2002;8(3):177.

- Patient satisfaction with and knowledge of their prescription drug coverage. 2001;7(1):34-42.

- The CIGNA Healthcare quality improvement and patient satisfaction project. 2000;6(4):312-15.

- Development of an interval-level scale to assess consumer satisfaction with prescription drug coverage. 2000;6(3):225-31.

- Drug-management strategies: consumers' perspectives. 2000;6(2):122-28.

- A comparison of satisfaction with mail versus traditional pharmacy services. 1997;3(3):327-37.

- Guide to consumers' pharmaceutical purchasing behavior. 1996;2(5):489-90, 494, 498-99.

\section{Drug Benefit Management Methods-Quantity Limits,}

\section{Step Therapy, and Prior Authorization (PA)}

- Cost and utilization of behavioral health medications associated with rescission of an exemption for prior authorization for severe and persistent mental illness in the Vermont Medicaid program. 2010;16(5):317-28.

- Pharmacist and physician satisfaction and rates of switching to preferred medications associated with an instant prior authorization program for proton pump inhibitors in the North Carolina Medicaid program. 2010;16(4):250-63.

- Studies recommending palivizumab have serious deficiencies. [letter and responses] 2010;16(7):509-14.

- Utilization management opportunities for palivizumab for prophylaxis of respiratory syncytial virus complications in infants. [editorial] 2010;16(1):59-66.

- A systematic review of compliance with palivizumab administration for RSV immunoprophylaxis. 2010;16(1):46-58.

- Medical utilization associated with palivizumab compliance in a commercial and managed Medicaid health plan. 2010;16(1):23-31.
- Description of the outcomes of prior authorization of palivizumab for prevention of respiratory syncytial virus infection in a managed care organization. 2010;16(1):15-22.

- Correction-author disclosures-Need to revisit step-therapy for ARBs. [letter] 2009;15(4):361.

- Prior authorization and clopidogrel use-the truth lies in the details. [editorial] 2009;15(1):71-77.

- Perceptions of Saskatchewan community pharmacists regarding a prior-authorization program. 2007;13(7):589-97.

- Need to revisit step therapy for ARBs. [letter, author response, and editors' response] 2007;13(6):528-31. Correction - author disclosures. 2009; 15(4):361.

- Outcomes of sword swallowing and pharmaceutical step-therapy interventions. [editorial] 2007;13(3):284-86.

- Assessing step-therapy programs: a step in the right direction. [commentary] 2007;13(3):273-75.

- Effects of a step-therapy program for angiotensin receptor blockers on antihypertensive medication utilization patterns and cost of drug therapy. 2007;13(3):235-44.

- Utilization and cost of sildenafil in a large managed care organization with a quantity limit on sildenafil. 2005;11(8):674-80.

- The Academy of Managed Care Pharmacy's Concepts in Managed Care Pharmacy: prior authorization and the formulary exception process. [letter] 2005;11(4):358-61.

- Prior authorization and the formulary exception process-examples from the real world. [editorial] 2005;11(4):349-51.

- Step-therapy edits for PPIs and COX-2 drugs-what we do and do not know. [editorial] 2004;10(4):356.

- Health plan member experience with point-of-service prescription step therapy. 2004;10(4):291-98.

- Transparency needed for economic analyses of PA programs. [letter] 2003;9(6):576

- Clinical, service, and cost outcomes of drug coverage edits and quantity limits. [editorial] 2003;9(4):368-69.

- Evaluation of a monthly coverage maximum (drug specific quantity limit) on the 5-HTl agonists (triptans) and dihydroergotamine nasal spray. 2003;9(4):335-45.

- Pharmacoeconomic modeling of prior-authorization intervention for COX-2 specific inhibitors in a 3-tier copay plan. 2003;9(4):327-34.

- Prior authorization to manage drug utilization and costs. 2003;9(1):95

- Analysis of a prescription drug prior authorization program in a Medicaid health maintenance organization. 2003;9(1):36-44.

- Managing care via prior-authorization (PA) programs? 2002;8(4):296.

- A neurologist's perspective on quantity limits. 2002;8(3):184.

- Triptan quantity limits. 2002;8(3):182-84.

- Medical and pharmacy cost and utilization outcomes of a quantity limit on 5-HTl agonists (triptans) by a managed care organization. 2001;7(6):468-75.

- Analysis of the effects of quantity limits. 2001;7(5):338, 340.

- Prior-authorization programs: a critical review of the literature. 2001;7(4):297-302.

- Evaluating the operational performance and financial effects of a drug prior-authorization program. 1997;3(6):699-706.

- Assessment of Medicaid prior-approval policies on prescription expenditures: market-share analysis of Medicaid and cash prescriptions. 1996;2(6):651-56.

- Effect of a prior-authorization requirement on the use of nonsteroidal anti-inflammatory drugs by Medicaid patients. 1996;2(2):158-63.

\section{Drug Promotion and Advertising}

(see also Direct-to-Consumer Advertising [DTCA])

- Drug company advertising in medical journals about the healtheconomic advantages of their products for 2000-2006 versus 1990 1999. 2008;14(8):749-55. 
- Common industry practices and OIG compliance guidance. [letter] 2003;9(4):375.

- Health care communications agencies respond to managed care. 1998;4(1):9-12.

- Information requirements of health systems as drug purchasers: does the FDA have a role in setting evidentiary standards? 1998;4(6):593-98.

\section{Drug Spending, Utilization, and Cost Trends}

- Prescription drug expenditures, financial burden, and health plan satisfaction among Medicare beneficiaries. 2003;9(5):453-54.

- Selected characteristics of senior citizen's prescription drug payment and procurement in 1998 and 2001. 2003;9(5):408-15.

- Burden of prescription drug costs in the United States. 2003;9(1):91-92.

- Prescription drug use among elderly and nonelderly families. 2003;9(1):19-28.

- Trends in managed care pharmacy: responding to changing environments. 2002;8(2):102-07.

- Drug costs out of control—check your assumptions. 2002;8(2):81.

- Trends in managed care pharmacy: preparing for the future. 2001;7(2):105-10

- Too much or too little? The role of pharmaceuticals in the health care system. 1999;5(4):296-97, 301-02.

- Local area market dynamics. 1998;4(2):115-17, 120.

\section{Drug Therapy-Natural Products}

- Managing natural products. 2001;7(5):414-19.

- Top-selling herbal supplements. 1999;5(4):357-66.

\section{Drug Therapy, Therapeutic Selection,} and P\&T Decision Making

- ACE inhibitor and ARB utilization and expenditures in the Medicaid fee-for-service program from 1991 to 2008. 2010;16(9):671-79.

- Overactive bladder disease: the urge for better therapies. [commentary] 2008;14(4):381-86.

- Here is the case for the urge in administrative claims database research about overactive bladder therapies. [commentary] 2008;14(3):309-11.

- Incorporating observational data into the formulary decision-making process - summary of a roundtable discussion. [commentary] 2008;14(3):302-08

- Persistence, adherence, and switch rates among extended-release and immediate-release overactive bladder medications in a regional managed care plan. 2008;14(3):291-301.

- Expert opinion regarding clinical and other outcome considerations in the formulary review of immune globulin. [commentary] 2007;13(3):278-83.

- Drug and medical cost effects of a drug formulary change with therapeutic interchange for statin drugs in a multistate managed Medicaid organization. 2006;12(4):331-40.

- Case report: lack of control of diabetes and weight gain in a patient on initiation and rechallenge of therapy with olanzapine. 2006;12(3):260-62.

- Pharmacist intervention in safe and effective conversion of brand to generic drugs. [letter] 2005;11(9):777.

- Cost-efficacy analysis of peginterferon alfa-2b plus ribavirin compared with peginterferon alfa-2a plus ribavirin for the treatment of chronic hepatitis C. 2005;11(8):687-94.

- Comparison of costs and utilization between users of insulin lispro versus users of regular insulin in a managed care setting. 2005;11(5):376-82.
- Cost-effectiveness analysis of ondansetron and prochlorperazine for the prevention of postoperative nausea and vomiting. 2005;11(4):317-21.

- Bipolar disorder pills in perspective: questions from peer review. [editorial] 2005;11(1):88-89.

- Prescription drugs marketed in the United States should be approved by the FDA. [editorial] 2003;9(4):366-67.

- Cost and utilization comparisons among propensity score-matched insulin lispro and regular insulin users. 2003;9(3):263-68.

- Improvements in glycemic control in type 2 diabetes patients switched from sulfonylurea coadministered with metformin to glyburide-metformin tablets. 2003;9(3):256-62.

- Modeling the annual costs of postmenopausal prevention therapy: raloxifene, aledronate, or estrogen-progestin therapy. 2003;9(2):150-58.

- Pharmacoeconomics and considerations for injectable products: focus on colony-stimulating factors. [supplement] 2003;9(2):S1-S25.

- Clinical and economic impact of glatiramer acetate versus beta interferon therapy among patients with multiple sclerosis in a managed care population. 2002;8(6):469-76.

- A pharmacoeconomic model comparing two long-acting treatments for overactive bladder. 2002;8(5):343-52.

- The search for better antipsychotics continues. [letter] 2002;8(4):298.

- Atypical antipsychotics and tardive dyskinesia. 2002;8(4):291-92.

- Neuroleptic drug exposure and incidence of tardive dyskinesia: a records-based case-control study. 2002;8(4):259-65.

- Ophthalmic agents and managed care. 2002;8(3):217-23.

- An in-home Synagis program for RSV prevention in high-risk infants. 2001;7(6):476-81.

- An assessment of emerging patterns of etanercept use in the treatment of rheumatoid arthritis. 2001;7(1):56-61.

- Using simple and relative difference to interpret changes in healthrelated quality-of-life scores for salmeterol, ipratropium, and placebo. 2000;6(6):483-87.

- Cost analysis of therapeutic interchange of calcium channel blockers for the treatment of hypertension: unexpected results from a conversion program. 2000;6(5):390-94.

- Outcomes analyses of the outpatient treatment of venous thromboembolic disease using the low-molecular-weight heparin enoxaparin in a managed care organization. 2000;6(4):298-304.

- Assessing the relevance of outcomes data for colony-stimulating factors. 2000;6(2):144-50.

- Economic assessment of the relationship between disease exacerbations and the cost of multiple sclerosis. 2000;6(1):19-24.

- Calcium channel blockers and angiotensin-converting enzyme inhibitors for hypertension in a multimarket managed care organization. 1999;5(6):537-40.

- Criteria for the use of tramadol in adult patients: medication-use evaluation guidelines. 1999;5(6):492-97.

- Safety and efficacy of a mandatory formulary switch from nifedipine GITS to amlodipine. 1999;5(3):225-29.

- Evaluation of blood pressure and adverse effects in patients converted from lisinopril to benazepril. 1999;5(1):52-54.

- The NTI debate. 1998;4(3):289-90.

- Human growth hormone: ethical and economic considerations of use and misuse. 1997;3(4):448-52.

- Outcomes and cost savings of an ACE inhibitor therapeutic interchange. 1997;3(2):219-23.

- Physicians' perspectives of a therapeutic conversion with a staffmodel HMO. 1997;3(1):55-56, 65.

- Retrospective analysis of formulary transition at large metropolitan HMO: nifedipine GITS to felodipine ER. 1996;2(6):642-46. 


\section{Drug Utilization Review (DUR) or Drug Utilization Management-Appropriate Drug Use}

- Chinese pharmacists propose patient consent for unlabeled use of medications. [letter] 2010;16(8):640.

- Regulatory actions on the off-label use of prescription drugs: ongoing controversy and contradiction in 2009 and 2010. [editorial] 2010;16(8):629-39.

- Drug use evaluation of tamoxifen focusing on off-label use in a managed care population in Israel. 2010;16(5):355-59.

- Quality improvement opportunities in prescriber alert programs. [editorial] 2010;16(4):292-96.

- Variation in prescriber responses to drug safety alert messages: disease, symptom, or red herring? [commentary] 2010;16(3):231-32.

- Geographic variation in drug safety: potentially unsafe prescribing of medications and prescriber responsiveness to safety alerts. 2010;16(3):196-205.

- Longitudinal analysis of the costs associated with inpatient initiation and subsequent outpatient continuation of proton pump inhibitor therapy for stress ulcer prophylaxis in a large managed care organization. 2010;16(2):122-29.

- Opioid dependence: managing the high cost of treatment failure. [supplement] 2010;16(1-b):S1-S32.

- Economic burden of prescription opioid misuse and abuse. 2009;15(7):556-62.

- Contradictory actions on off-label use of prescription drugs? The FDA and CMS versus the U.S. Justice Department. [editorial] 2009;15(2):161-65.

- Examination of multiple medication use among TRICARE beneficiaries aged 65 years and older. 2007;13(2):155-62.

- Use of low-molecular-weight heparin during dental extractions in a Medicaid population. 2007;13(1):53-58.

- False-positive versus true-positive drug-drug interactions with warfarin. [editorial] 2006;12(8):686-87.

- Prevalence of drug-related problems and cost-savings opportunities in Medicaid high utilizers identified by a pharmacist-run drug regimen review center. 2006;12(8):677-85.

- Administrative claims analysis of the relationship between warfarin use and risk of hemorrhage including drug-drug and drug-disease interactions. 2006;12(8):640-48.

- Assessing potentially inappropriate prescribing in the elderly Veterans Affairs population using the HEDIS 2006 quality measure. 2006;12(7):537-45.

- Evaluation of the performance of drug-drug interaction screening software in community and hospital pharmacies. 2006;12(5):383-89

- Comparison of rates of potentially inappropriate medication use according to the Zhan criteria for VA versus private sector Medicare HMOs. 2006;12(5):362-70.

- Pharmacist response to alerts generated from Medicaid pharmacy claims in a long-term care setting: results from the North Carolina Polypharmacy Initiative. 2005;11(7):575-83.

- Direct costs of opioid abuse in an insured population in the United States. 2005;11(6):469-79.

- Implementation of the Beers criteria: sticks and stones-or throw me a bone. [editorial] 2005;11(5):416-17.

- Evidence-based medicine: which drugs are truly contraindicated for use in older adults? [editorial] 2005;11(3):259-60.

- Effect of prescriber education on the use of medications contraindicated in older adults in a managed Medicare population. 2005;11(3):211-19.

- Prescribing of antipsychotic medication in a Medicaid population: use of polytherapy and off-label dosages. 2005;11(1):17-24.

- Longitudinal analysis of the use of etanercept versus infliximab determined from medical chart audit. 2004;10(6):538-42.
- Current status of prospective drug utilization review. 2004;10(5):433-41.

- Frequency of simvastatin prescriptions with potentially interacting medications in a Veterans Affairs health care system. 2004;10(3):239-43

- Use of drugs for off-label indications: living in the same world. [editorial] 2003;9(6):570-71.

- Gabapentin may be appropriate for off-label uses. [editorial] 2003;9(6):569-70.

- Examination of the evidence for off-label use of gabapentin. 2003;9(6):559-68.

- Retrospective drug utilization review: incidence of clinically relevant potential drug-drug interactions in a large ambulatory population. 2003;9(6):513-22.

- Analysis of medication use patterns: apparent overuse of antibiotics and underuse of prescription drugs for asthma, depression, and CHF. 2003;9(3):232-37.

- Gabapentin and indications of appropriate use. 2002;8(4):293-94.

- Gabapentin use in a managed Medicaid population. 2002;8(4):266-71.

- Better data for making better decisions: finger-pointing or useful drug use review. [editorial] 2002;8(3):208-10.

- High frequency of itraconazole prescriptions with potentially interacting medications in a large health care plan. 2002;8(3):199-203.

- DUR messages—better data needed for making better decisions. [editorial] 2002;8(3):178-79.

- Potentially inappropriate medication use in a Medicare managed care population: association with higher costs and utilization. 2001;7(5):407-13.

- A provincial program in Nova Scotia to decrease the use of wet nebulization respiratory medications. 2000;6(6):457-58, 460-61, 464.

- Incidence of anxiolytic/hypnotic therapy and its relationship to duration of antidepressant therapy in a national managed care organization. 2000;6(2):138-42.

- Medicaid drug utilization review and managed care: the perspectives and experiences of state program directors. 2000;6(2):131-36.

- Evaluation of online prospective DUR programs in community pharmacy practice. 2000;6(1):27-32.

- The pharmacist's assessment of second generation online prospective drug utilization review. 1998;4(2):183-91.

\section{Dyslipidemia}

- Tough questions about the value of statin therapy for primary prevention: did JUPITER miss the moon? [editorial] 2010;16(6):417-23.

- Maintaining cardiovascular health in patients with mixed dyslipidemia: optimizing the management of hypertriglyceridemia and non-HDL cholesterol. [supplement] 2009;15(1)(suppl S-c):S1-S21.

- Targeting low HDL-cholesterol to decrease residual cardiovascular risk in the managed care setting. [supplement] 2008;14(8-S):S1-S31.

- LDL-C goal attainment among patients newly diagnosed with coronary heart disease or diabetes in a commercial $\mathrm{HMO}$ 2007;13(8):652-63.

- Results of retrospective chart review to determine improvement in lipid goal attainment in patients treated by high-volume prescribers of lipid-modifying drugs. 2006;12(9):745-51.

- Forecasting cholesterol management-end of the statin gold rush? [editorial] 2006;12(6):479-85.

- Lipid levels and use of lipid-lowering drugs for patients in pharmacist-managed lipid clinics versus usual care in 2 VA medical centers. 2005;11(9):763-71. 
- Clinical and economic outcomes of conversion of simvastatin to lovastatin in a group-model health maintenance organization. 2005;11(8):681-86.

- Fish oil for heart disease-happy to be in second place. [editorial] 2005;11(7):584-85.

- Similar medication compliance and control of dyslipidemia with simvastatin or atorvastatin in a staff-model HMO medical clinic. 2005;11(6):499-504.

- Persistence with lipid-lowering therapy: influence of the type of lipid-lowering agent and drug benefit plan option in elderly patients. 2004;10(5):404-11.

- Methods to attain optimal outcomes with lipid-lowering drug therapy. [editorial] 2004;10(3):267-70.

- Cost-effectiveness analysis of simvastatin and lovastatin/extendedrelease niacin to achieve LDL and HDL goal using NHANES data. 2004;10(3):251-58

- Quantifying the effect of applying the NCEP ATP III criteria in a managed care population treated with statin therapy. 2004;10(3):244-50.

- Challenges in evaluating the cost-effectiveness of statins. [editorial] 2004;10(1):81-82.

- Evaluating the cost-effectiveness of statins. [editorial] 2004;10(1):79-81.

- Determinants of the cost-effectiveness of statins. 2003;9(6):544-51.

- Optimizing dyslipidemia outcomes: a novel pharmacotherapy pathway. [supplement] 2003;9(1):S1-S28.

- Effective cholesterol management with fewer dollars. 2002;8(6):519.

- High blood cholesterol and ATP III: guidelines for health benefit and health care providers. 2001;7(6):482-89.

- Comparative cost-effectiveness of fluvastatin and lovastatin in patients with hypercholesterolemia. 2000;6(3):241-46.

- A comparison of hypercholesterolemia management in the secondary prevention of coronary heart disease by payor types: fee-for-service, Medicare, and managed care organizations. 1998;4(5):483-87.

- The cost-effectiveness impact of a preferred agent HMG-CoA reductase inhibitor policy in a managed care population. 1997;3(5):548-53.

- Comparative cost-effectiveness of bile acid sequestering resins, HMG Co-A reductase inhibitors, and their combination in patients with hypercholesterolemia. 1995;1(3):188-92.

\section{Ethics}

- A question of ethics. 2001;7(6):436.

- Ethics and the use of drug formularies. 1996;2(2):76, 78, 81-82.

\section{Formulary Management-Methods}

\section{and Effects-Pharmacoeconomics}

- The AMCP Format for Formulary Submissions, version 3.0 [supplement] 2010;16(1-a):S1-S32.

- Results of an intervention in an academic internal medicine clinic to continue, step-down, or discontinue proton-pump inhibitor therapy related to a Tennessee Medicaid formulary change. 2009;15(4):344-50.

- Selling real-world health care research to reluctant buyers evidence-based education or marketing a defective product? [editorial] 2009;15(3):294-96.

- Standardizing quality assessment of observational studies for decision making in health care. [commentary] 2009;15(3):275-83.

- Formulary management in the Department of Defense. 2009;15(2):133-46.

- Proton-pump inhibitor utilization associated with the change to nonpreferred formulary status for esomeprazole in the TRICARE formulary. 2009;15(1):42-54.
- Physicians' opinions about responsibility for patient out-ofpocket costs and formulary prescribing in two Midwestern states. 2008;14(8):780-89.

- It's only a pharmacoeconomic model—believe it or not. [editorial] 2008;14(1):83-87.

- Cost-effective pharmacologic therapies to treat chronic hepatitis B: how far have we really come? [commentary] 2008;14(1):65-69.

- The search for cost-effective treatment of chronic hepatitis B. [commentary] 2008;14(1):61-64.

- Evaluation of the cost-effectiveness of entecavir versus lamivudine in hepatitis BeAg-positive chronic hepatitis B patients. 2008;14(1):21-33.

- Evaluation of clostridium difficile-associated diarrhea with a drug formulary change in preferred fluoroquinolones. 2008;14(1):34-40.

- Opinions regarding the value and use of the AMCP Format still unknown. [commentary] 2007;13(7):609-10.

- Opinions regarding the Academy of Managed Care Pharmacy dossier submission guidelines: results of a small survey of managed care organizations and pharmaceutical manufacturers. 2007;13(4):360-71.

- Manufacturer response to AMCP Format dossier requests. [letter] 2007;13(3):290-92.

- AMCP Format dossier requests: manufacturer response and formulary implications for one large health plan. 2007;13(1):37-43.

- Effect of patient notification of formulary change on formulary adherence. 2005;11(6):493-98.

- The AMCP Format for Formulary Submissions, version 2.1 [supplement] 2005;11(5, S-b):I-XVI, 1-29, Appendix.

- P\&T committees-black boxes versus AMCP Format, and what is the true cost and value of pimecrolimus. [editorial] 2005;11(1):93-94.

- Health plan budget impact analysis for pimecrolimus. 2005;11(1):66-73.

- The role of pharmacy benefit managers in formulary design: service providers or fiduciaries? [letter] 2004;10(4):359-60.

- Cost-effectiveness analysis and the formulary decision-making process. 2004;10(1):48-59.

- Determinants of the cost-effectiveness of statins. 2003;9(6):544-51.

- Formulary management methods and pharmacoeconomics. 2003;9(5):452-53.

- Using decision-analytic models wisely. 2003;9(5):449-50.

- Do decision-analytic models identify cost-effective treatments? A retrospective look at Helicobacter pylori eradication. 2003;9(5):430-40.

- Shortcomings in pharmacy benefit forecasting - interferon beta products. [letter and author response] 2003;9(4):373-74.

- Alternate financial incentives in multi-tiered formulary systems to improve accountability for outcomes. 2003;9(4):360-65.

- Pharmacy benefit forecast for a new interferon beta-la for the treatment of multiple sclerosis: development of a first-line decision tool for pharmacy-budget planning using administrative claims data. 2003;9(2):168-74.

- Industry's perception of presenting pharmacoeconomic models to managed care organizations. 2003;9(2):159-67.

- Quality of Health Economic Studies (QHES)—-tool or mask? 2003;9(1):93.

- Summary quality scores for pharmacoeconomic studies: balancing validity with need. 2003;9(1):87-88.

- Assessing the value of the Quality of Health Economic Studies (QHES). 2003;9(1):86-87.

- Examining the value and quality of health economic analyses: implications of utilizing the QHES. 2003;9(1):53-61.

- Meta-analysis of oral triptan therapy for migraine: number needed to treat and relative cost to achieve relief within 2 hours 2003;9(1):45-52.

- Economic evaluation of citalopram use and expenditures among recipients in the Texas Medicaid program. 2002;8(6):494-500. 
- Exploring the methodological challenges of investigating comparison groups with different underlying characteristics: a case study. 2002;8(5):353-59.

- AMCP guidance for submission of clinical and economic evaluation data to support formulary listing in U.S. health plans and pharmacy benefits management organizations. 2001;7(4):272-82.

- The effect of a closed formulary in the face of real-life enrollment and disenrollment patterns. 2000;6(4):293-97.

- The pros and cons of formularies. 2000;6(3):203-07.

- The role of pharmacoeconomic information in the formulary decision-making process. 2000;6(2):108, 113-14, 117-18, 121

- The impact of a therapeutic interchange program in a managed care organization. 1999;5(5):438-41.

- Outcome analysis of a formulary transition from nifedipine to felodipine at a Veterans Affairs Medical Center. 1999;5(5):425-28.

- Managed care formularies in the United States.

1999;5(4):289-92, 295.

- Formulary management by an on-site school of pharmacy faculty member in a Medicaid managed care organization. 1998;4(4):407-10.

- Innovative drug formulary management through computer-assisted protocols. 1998;4(3):246-47, 251-52.

- Applications of pharmacoeconomics for managed care pharmacy. 1997;3(6):720-26.

- DOD's Pharmacoeconomic Center: translating research into good patient care practices. 1997;3(6):662-64, 666.

- Managing the pharmacy benefit: the formulary system. 1997;3(5):565-73.

- Drug formularies: real opportunities to improve MCO efficiency. 1997;3(3):254, 375-76.

- Pharmacoeconomic analysis of hormone replacement therapyimplications for managed care. 1997;3(2):200-09.

- Pharmacoeconomic evaluations: guidelines for drug purchasers. 1996;2(6):671-77.

- A predictive cost analysis model for estimating formulary impact of new products in managed care. 1998;4(6):585-90.

- Using outcomes as a tool to evaluate formulary selection decisions: hypercholesterolemia as a case example. 1996;2(4):396-404.

- Development of a community-based formulary comparison instrument. 1995;1(3):211.

\section{Formulary Management-P\&T Committees}

- The pharmacy and therapeutics committee competition goes national: building toward Tampa and beyond. 2001;7(6):448-51.

- Pharmacy \& therapeutics committees: a mock meeting at AMCP. 1996;2(4):380, 383-84.

Gout

- Disease-related and all-cause health care costs of elderly patients with gout. 2008;14(2):164-75.

\section{Health Care Delivery and Health Promotion}

- Shape It Up - A school-based education program to promote healthy eating and exercise developed by a health plan in collaboration with a college of pharmacy. 2009;15(5):403-13.

- A review of the use of CAM therapy and the sources of accurate and reliable information. 2005;11(8):695-703.

- Development of a complementary and alternative medicine (CAM) pharmacy and therapeutics (P\&T) subcommittee and CAM guide for providers. 2005;11(3):252-58.

- David and Goliath-employer takes on health care cost management. [editorial] 2004;10(6):557-58.

- A managed care stakeholder assessment of preventive medicine: practical applications, measurable results, evaluating success. [supplement] 2002;8(4):S1-S13.
- Pharmacy: looking back to see the future. 1998:4(5):454-55, 459-60, 462.

- International markets offer new opportunities for MCOs and PBMs. 1997;3(4):403-04, 409-10.

- Integration takes managed care in different directions: horizontal, vertical, and beyond. 1997;3(3):260, 263-64.

- Looking back: failed health care reform put managed care on the map. 1997;3(2):159, 160, 163.

- Alternative medicine in managed care pharmacy. 1997;3(1):77-80, 83-86.

- Indian Health Service: paving the way for pharmaceutical care. 1997:3(1):36, 41-43.

- While health care evolves, antitrust law endures. 1996;2(6):679-86.

- Managed care cautiously embraces complementary medicine. 1996;2(6):626, 631-33.

- Rocky Mountain HMO. 1996;2(5):500, 502-04, 507.

- Veterans Affairs Health System: embracing new challenges, new changes. 1996;2(2):111-12, 117-18.

\section{Health Care Spending and Health Economics}

- Economic burden of postoperative ileus associated with colectomy in the United States. 2009;15(6):485-94.

- Fractal mathematics in managed care? How a simple and revealing analysis could improve the forecasting and management of medical costs and events. [editorial] 2009;15(4):351-58.

- Utilization, cost trends, and member cost-share for self-injectable multiple sclerosis drugs-pharmacy and medical benefit spending from 2004 through 2007. 2007;13(9):799-806.

- Medical costs and resource utilization for hemophilia patients with and without HIV or HCV infection. 2007;13(9):790-98.

- Burden of illness: costs and consequences of our fragmented mental health care system. [supplement] 2006;12(2):S1-S40.

- Economic burden of anemia in an insured population. 2005;11(7):565-74.

- The cost of falls among the community-dwelling elderly. 2005;11(4):307-16.

- Is there no prescription to decrease health care outlays in the face of an aging population? 2000;6(6):450-51.

- Health economics II: some unique aspects of health economics. 2000;6(2):173-78.

- Health economics I: basic economic principles. Evaluation of online prospective DUR programs in community pharmacy practice. 2000;6(1):43-50.

\section{Health Insurance and Health Care Finance}

- Reaching out to the uninsured: patient-assistance program goes independent. [letter] 2010;16(6):425-26.

- Managed care and health care reform: everything old is new again. [editorial] 2009;15(9):766-75.

- The Health Insurance Portability and Accountability Act of 1996: the issue of portable health care coverage. 1999;5(2):81, 85-88.

- Direct contracting: the next purchaser strategy. 1996;2(1):11-12, 14, 16.

\section{Heartburn and Acid-Related Disorders}

- Employers need to have a wider horizon than drug costs alone when considering the implementation of health care intervention programs. [letter and author response] 2006;12(7):581-83.

- PPIs are therapeutically interchangeable and ideal for a managed care intervention such as therapeutic MAC. [editorial] 2006;12(7):578-80.

- Pharmacoeconomics-Determination of the cost-effectiveness of Helicobacter pylori eradication. 2003;9(5):461-52.

- Validation of a single-patient drug trial methodology for personalized management of gastroesophageal reflux disease. 2002;8(6):459-68. 
- Cost-benefit computer modeling of Helicobacter pylori testing and treatment in patients on long-term H2-blocker prophylaxis. 2000;6(5):383-89.

- Gastroesophageal reflux disease in a managed care setting: charges by place and type of service. 1998;4(3):336-43.

- Defining strategies for peptic ulcer treatment: a Helicobacter pylori economic-cost model. 1998;4(2):205-20.

- Gastroesophageal reflux disease in a managed care setting: professional, facility, and pharmacy charges. 1998;4(1):64-70.

- Peptic acid disorders: developing a disease management program. 1996;2(5):569-75.

- AMCP's annual meeting: controversies surrounding Helicobacter pylori. 1996;2(4):377-79.

- Economic implications of self-treatment of heartburn/nonulcer dyspepsia with nonprescription famotidine in a managed care setting. 1996;2(3):263-71.

\section{Hypertension and Cardiovascular Disease}

- Applying quality measures and guidelines in the management of acute coronary syndrome and venous thromboembolism. [supplement] 2008;14(6, S-a):S1-S29.

- Quantifying the opportunity for pharmacists to improve management of hypertension in a primary care medical clinic. [letter] 2008;14(3):322-23.

- Renin-angiotensin aldosterone system and hypertension: current approaches and future directions. [supplement] 2007;13(8, S-b):S1-S40.

- Initiation of statins after hospitalization for coronary heart disease. 2007;13(5):385-96.

- Pharmacoeconomic analysis of clopidogrel in secondary prevention of coronary artery disease. 2007;13(4):326-36.

- The role of beta blockade in endothelial function. [supplement] 2007;13(5):S1-S24.

- Relationship of blood pressure control to adherence with antihypertensive monotherapy in 13 managed care organizations 2006;12(3):239-45.

- Health care resources and costs for treating peripheral artery disease in a managed care population: results from analysis of administrative claims data. 2005;11(9):727-34.

- Spending money to save money_cardiovascular disease management. [editorial] 2004;10(6):555-57.

- Assessment of drug therapy management and the prevalence of heart failure in a managed care population with hypertension. 2004;10(6):513-20.

- An evidence-based approach: the emerging role of renal protection in hypertension: a focus on clinical and economic factors that impact formulary decision making. [supplement] 2004;10(5, S-a):S1-S29.

- A literature review of cardiovascular disease management programs in managed care populations. 2004;10(4):326-44.

- Antihypertensive drug effects on renal function and myocardial infarction and implications of the ALLHAT study results. 2003;9(1):93-95.

- Impact of the ALLHAT study results on managed care. 2003;9(1):84-86.

- Risk of myocardial infarction with combination antihypertensive regimens including a dihydropyridine calcium channel blocker in hypertensive diabetics. 2003;9(1):29-35

- Evaluation of initial drug selection for newly medicated hypertensives at the Westinghouse Electric Corporation. 1999;5(6):505-09.

- The clinical and economic implications of drug utilization patterns in the treatment of hypertension with ACE inhibitors and calcium channel blockers in a managed care setting. 1998;4(2):194-202.
- Trends in the treatment of hypertension within managed care organizations: a national survey of HMO pharmacy directors. 1997;3(3):317-22.

- Evaluating health-related quality of life in three disease management areas: asthma, diabetes, and hypertension. 1996;2(4):408-13.

\section{Infectious Disease}

- Redefining success for VAP: 360-degree approach. [supplement] 2009;15(5)(suppl):S1-S17.

- Pharmacist intervention in treatment of patients with genotype 1 chronic hepatitis C. 2009;15(2):147-50.

- START (Stewardship Tactics for Antimicrobial Resistance Trends). [supplement] 2009;15(2)(suppl):S1-S29.

- Reporting the evidence for optimal treatment options and formulary management: antiviral drugs in HIV and hepatitis B. [supplement] 2008;14(5, S-a):S1-S24.

- From adherence to outcomes: impact of benefit design on the HIV patient. [supplement] 2006;12(7, S-b):S1-S19.

- Severe sepsis in managed care: analysis of incidence, one-year mortality, and associated costs of care. 2004;10(6):521-30.

- Acute uncomplicated UTI and E. coli resistance: implications for firstline empirical antibiotic therapy. 2004;10(1):17-25.

- The economic impact of acute exacerbations of chronic bronchitis in the United States and Canada: a literature review. 2003;9(4):353-59.

- Early switch and early discharge opportunities in intravenous vancomycin treatment of suspected methicillin-resistant staphylococcal species infections. 2003;9(4):317-26.

- Evaluation of a rule-based program to describe antibiotic utilization for otitis media among three medical plans. 1999;5(3):232-40.

- Medication outcomes assessment of community-acquired infections. 1999;5(2):122-26.

- Fluoroquinolone-use evaluation for acute cystitis. 1996;2(5):564-68.

\section{Institutional Managed Care}

- Managed pharmaceutical care within a criminal justice system. 2001;7(3):182.

\section{Internet Pharmacy}

- Concern about foreign-source pharmacy Internet providers. 2001;7(5):335-36.

- The Internet and PBMs: new business model or business as usual? 2000;6(2):102, 105-07.

- With the click of a mouse. Evaluation of online prospective DUR programs in community pharmacy practice. 2000;6(1):73.

\section{Irritable Bowel Syndrome}

- Irritable bowel syndrome and antidepressants. [editorial] 2008;14(9):882-85.

- Self-reported use of pharmaceuticals among patients with irritable bowel syndrome in primary care. 2008;14(9):870-77.

- Disease management opportunities for IBS—-placebo versus active therapy. [editorial] 2004;10(4):356-57.

- The burden of illness of irritable bowel syndrome: current challenges and hope for the future. 2004;10(4):299-309.

\section{Lifestyle Drugs}

- Prevalence of phosphodiesterase-5 inhibitor use in the VHA in 2004 and 2005 is twice that of a commercial health plan in 2001. [letter] 2006;12(8):692-93

- Clinical monograph for drug formulary review: erectile dysfunction agents. 2005;11(2):151-71.

- Enhancing life or eradicating ugliness?: lifestyle drugs. 2002;8(1):15-16, 19-20. 


\section{Managed Care Pharmacy Practice}

- Effect of 6 managed care pharmacy tools: a review of the literature. [supplement] 2010;16(6-a):S1-S20.

- Quality articles require peer reviewers-as well as authors. [letter] 2005;11(2):186.

- John Ogden talks about managed care in the Veterans Administration. 2002;8(2):91-93.

- The value of managed care pharmacy in an IPA setting. 2001;7(6):438-39.

- Innovative managed care pharmacy practice. 2001;7(2):90-92.

- Innovative managed care pharmacy practice. 2001;7(1):8, 9.

- Career changes in managed care pharmacy. 2000;6(3):208, 210, 215.

- Managed care and the pharmacy profession revisited. 1999;5(2):78.

- Advancing outcomes research in managed care pharmacy: a call to action. 1998;4(3):257-58, 261-63, 266-67.

- The importance of communication skills for the managed care pharmacist. 1998;4(2):102.

- The evolution of pharmaceutical care into managed care environments. 1998;4(1):55-58.

- The changing face of managed care pharmacy and the role of PBMs. 1997;3(5):494, 497-98

- Managed care pharmacists: leading the way for a new millennium. 1997;3(4):383-85, 388.

- Consultant pharmacy and managed care: a partnership for the future. 1997;3(2):164, 167-69.

- Managed care pharmacy: leading pharmaceutical care integration forward. 1997;3(2):139, 141-42, 145-47.

- Group Health Cooperative. 1996;2(6):634-36, 639-40.

- Internal marketing: essential challenge for managed care pharmacy. 1996;2(5):473-74, 479-80.

- Prescription Solutions: managing pharmacy care through flexibility and innovation. 1996;2(4):385-86, 389-90, 395.

- Harvard Pilgrim Health Care: a new partnership in promoting pharmaceutical care. 1996;2(3):249-50, 252, 254.

- Blue Cross and Blue Shield: making pharmaceutical care a key component of managed care. 1996;2(1):33-34, 36, 38

- CIGNA HealthCare: a leader in pharmacy re-engineering. 1995;1(3):174-75, 178, 180

- Issues and concerns of managed care pharmacy directors: results of a national survey. 1995;1(2):116-20.

- Systemed: the future in PBMs. 1995;1(2):109-10, 113-14.

- Professional opportunities in managed care pharmacy. 1995;1(2):80, 82, 86-87.

- Kaiser Permanente medical care program. 1995;1(1):26-28, 30.

\section{Managed Health Care}

- Pay for performance: where's the return? [supplement] 2007;13(2, S-b):S1-S23.

- Medicare PPOs and managed care. 2003;9(1):91.

- Examining the managed health care continuum. 1997;3(5):511-12, 515-16, 518.

- Physician-management companies: ready to make their move in managed care. 1996;2(2):95-96, 98, 100, 106-07.

\section{Medicaid; and Medication Therapy Management (MTM)}

- Evaluation of the first year of a pilot program in community pharmacy: HIV/AIDS medication therapy management for Medi-Cal beneficiaries. 2009;15(1):32-41.

- State-by-state look at Medicaid retail pharmacy delivery: trials and triumphs. 1998;4(6):546-47, 551-52, 554.

\section{Medicare; and Medication Therapy Management Programs (MTMP) (see also Clinical Pharmacy Interventions - Clinical, Service and Cost Outcomes)}

- Medicare Part D coverage gap discount program beginning in 2011. [letter] 2010;16(5):367-68.

- The challenge of Medicare Part D for community pharmacies. [letter] 2009;15(2):171-72.

- Medicare Part D - a roundtable discussion of current issues and trends. [supplement] 2009;15(1)(suppl S-a):S1-S21.

- Medicare Part D: Good for patients and an opportunity for pharmacists. [commentary] 2009;15(1):66-70.

- A bleak future for independent community pharmacy under Medicare Part D. [commentary] 2008;14(9):878-81.

- Estimating the impact of Medicare Part D on the profitability of independent community pharmacies. 2008;14(8):768-79.

- Effect of an intervention to increase statin use in Medicare members who qualified for a medication therapy management program. 2008;14(6):532-40.

- Current issues and trends in Medicare Part D. [supplement] 2008;14(6, S-c):S1-S29.

- Sound medication therapy management programs, version 2.0 with validation study. [supplement] 2008;14(1, S-b):S1-S44.

- Medicare Part D: selected issues for plan sponsors, pharmacists, and beneficiaries in 2008. 2008;14(1):50-60.

- Unprecedented opportunities for managed care and community pharmacy to work together. 2007;13(5):426-28.

- Correction necessary regarding CMS guidance for coverage of new multiple-source brand drugs. [letter] 2007;13(3):290.

- Medication therapy management programs: when will the outcomes come out? [commentary] 2007;13(3):276-77.

- Characteristics of older adults who meet the annual prescription drug expenditure threshold for Medicare medication therapy management programs. 2007;13(2):142-54.

- Medicare Part D: selected issues for pharmacists and beneficiaries in 2007. 2007;13(1):59-65.

- Medicare Part D on the front line. [letter] 2006;12(5):407-08.

- Timeline and potential impact of CMS's drug Competitive Acquisition Program (CAP). 2006;12(3):263-64.

- Sound Medication Therapy Management Programs-2006 consensus document. [supplement] 2006;12(3):S1-S15.

- Medication Therapy Management Services for long-term care patients: no road maps for those trying to find their way. [editorial] 2005; 11(7):586-87.

- Medication therapy management programs-will patient need be satisfied? [editorial] 2005;11(4):352-53.

- Medication therapy management programs: to optimize pharmacy outcomes. [letter] 2005;11(2):179-86.

- Medicare and managed care update 2000 2000;6(6):466, 468, 470, 472

- Prescription coverage options for Medicare beneficiaries. 1999;5(3):250-54.

- Medicare and managed care: emerging partnerships. 1998;4(2):105, 108-10, 112.

- Overview of Medicare for managed care professionals. 1996;2(2):165-72

\section{Migraine Syndrome}

- There is value in anecdotal reports of relief from migraine with botulinum toxin. [letter and author response] 2009;15(1):78-79.

- Botox, migraine, and the American Academy of Neurology: an antidote to anecdote. [commentary] 2008;14(5):465-67.

- Humanistic, utilization, and cost outcomes associated with the use of botulinum toxin for treatment of refractory migraine headaches in a managed care organization. 2008;14(5):442-50. 
- Assessment of clinical, service, and cost outcomes of a conversion program of sumatriptan to rizatriptan ODT in primary care patients with migraine headaches. 2006;12(3):246-53.

- Which is more elusive, the pot of gold at the end of a rainbow or determining the most cost-effective triptan? [editorial] 2005;11(6):513-15.

- Best value for money in triptans. [editorial] 2005;11(5):419-21.

- Triptans for migraine therapy: a comparison based on number needed to treat and doses needed to treat. 2005;11(5):394-402.

- Costs and utilization of triptan users who receive drug prophylaxis for migraine versus triptan users who do not receive drug prophylaxis. 2005;11(2):137-44.

- Prevalence and burden of illness of migraine in managed care patients. 2005;11(2):124-36.

- Migraine matters: the role of triptans in relieving the burden in managed care. [supplement] 2004;10(4, S-b):S1-S16.

- Which triptan?-Opportunity for same or better outcomes at lower cost. [editorial] 2004;10(3):266.

- A comparison of the cost-effectiveness of almotriptan and sumatriptan in the treatment of acute migraine using a composite efficacy/tolerability end point. 2004;10(3):259-65.

- Meta-analysis of oral triptan therapy for migraine: number needed to treat and relative cost to achieve relief within 2 hours. 2003;9(1):45-52.

\section{Multiple Sclerosis}

- Price increases and new drugs drive increased expenditures for multiple sclerosis. 2010;16(9):713-17.

- All-cause health care utilization and costs associated with newly diagnosed multiple sclerosis in the United States. 2010;16(9):703-12.

- Gender differences in self-reported symptom awareness and perceived ability to manage therapy with disease-modifying medication among commercially insured multiple sclerosis patients. 2010;16(3):206-16.

- Current and future directions in MS management: key considerations for managed care pharmacists. [supplement] 2009;15(9-a):S1-S17.

- Comparing the cost-effectiveness of disease-modifying drugs for the first-line treatment of relapsing-remitting multiple sclerosis. 2009; 15(7):543-55.

- Review of the clinical debate regarding interventions for multiple sclerosis. [supplement] 2009;15(1)(suppl S-b):S1-S17.

- Pharmacoeconomic modeling of drug therapies for multiple sclerosis —are we building houses on sand? [editorial] 2007;13(3):287-89.

- Cost-effectiveness of four immunomodulatory therapies for relapsingremitting multiple sclerosis: a Markov model based on long-term clinical data. 2007;13(3):245-61.

- Descriptive analysis of the direct medical costs of multiple sclerosis in 2004 using administrative claims in a large nationwide database. 2007;13(1):44-52.

- Meeting the challenge of incorporating injectable biologics into managed care: multiple sclerosis and psoriasis. [supplement] 2004;10(3, S-b):S1-S45.

- The Society of Industrial Pharmacy Students: A new organization at the University of Houston. [letter] 2003;9(4):372.

- Pharmacy benefit forecast for a new interferon beta-la for the treatment of multiple sclerosis: development of a first-line decision tool for pharmacy-budget planning using administrative claims data. 2003;9(2):168-74

- Paying for value in the management of multiple sclerosis. 2002;8(6):520.

- Clinical and economic impact of glatiramer acetate versus beta interferon therapy among patients with multiple sclerosis in a managed care population. 2002;8(6):469-76.

\section{Obesity}

- Association between cardiometabolic risk factors and body mass index based on diagnosis and treatment codes in an electronic medical record database. 2008;14(8):756-67.

- The role of pharmaceuticals in reducing cardiometabolic risk: rethinking pharmacy benefit design to reduce the burden on the health care system. [supplement] 2006;12(1):S1-S16.

- "U Can't Touch This" with pharmacotherapy alone for weight loss or smoking cessation. [editorial] 2005;11(6):516-20.

- Cost-effectiveness of sibutramine in the LOSE Weight Study: evaluating the role of pharmacologic weight-loss therapy within a weight management program. 2005;11(6):458-68.

- The efficacy and safety of anorexiant medication in the treatment of obesity: implications for managed care formularies. 1998;4(4):422-28.

- A cost-effective analysis of appetite suppressants for obesity treatment in a managed care organization. 1998;4(3):293-300.

\section{Osteoporosis}

- 3-year results of a member and physician intervention to reduce risk associated with glucocorticoid-induced osteoporosis in a health plan. 2008;14(3):281-90.

- Therapeutic options in the prevention and treatment of postmenopausal osteoporosis. [supplement] 2006;12(6, S-a):S1-S28.

- Reducing the risk of fractures-the options narrow for cost-effective therapeutic alternatives. [editorial] 2004;10(2):168-71.

- Comparison of risedronate to alendronate and calcitonin for early reduction of nonvertebral fracture risk: results from a managed care administrative claims database. 2004;10(2):142-51.

- Drug formulary decisions-evaluating the risks and benefits of hormone replacement therapy. [editorial] 2004;10(1):85-86.

- Clinical monograph: hormone replacement therapy. 2004;10(1):33-47.

- ERT, HRT, raloxifene, calcitonin, or bisphosphonates for osteoporosis. 2003;9(2):178-81.

- The cost of treating osteoporosis in a managed health care organization. 2003;9(2):142-49.

- Prevention and treatment of osteoporosis in managed care settings. 2002;8(1):58-65.

- Alendronate use among 812 women: prevalence of gastrointestinal complaints, noncompliance with patient instructions, and discontinuation. 1998;4(5):488-92.

\section{Pain Management}

- Review of regulatory programs and new opioid technologies in chronic pain management: balancing the risk of medication abuse with medical need. [commentary] 2010;16(4):276-87.

- Consequences of misunderstanding pain-And another view of "The Emperor's New Clothes." [commentary] 2009;15(8):688-89.

- Is buprenorphine-naloxone ready for prime time in the treatment of opioid addiction in managed care? [editorial] 2008;14(2):195-97.

- Opioid drug utilization and cost outcomes associated with the use of buprenorphine-naloxone in patients with a history of prescription opioid use. 2008;14(2):186-94.

- Fentanyl transdermal vs. oxycodone hydrochloride controlledrelease. [letter] 2003;9(5):457-58.

- Patient-reported utilization patterns of narcotic drugs. [letter] 2003;9(4):374-75.

- Patient-reported utilization patterns of fentanyl transdermal system and oxycodone hydrochloride controlled-release among patients with chronic nonmalignant pain. 2003;9(3):223-31.

- Beyond narcotics for effective pain management. 2003;9(2):175-76.

- Out of illness, into life: pain management and the need for triptans. 2003;9(1):89-90.

- It's a pain. 1999;5(6):558. 


\section{Parkinson's Disease, Seizure Disorders, and Epilepsy}

- Treatment strategies and quality-of-care indicators for patients with Parkinson's disease. [supplement] 2009;15(3):S1-S21.

- Comparison of clinical practice guidelines in the initial pharmacological management of new-onset epilepsy in adults. [author response] 2006;12(3):270-71.

- Step therapy is not appropriate for antiepileptic drugs. [letter] 2006;12(3):269-70.

- A comparison of clinical practice guidelines in the initial pharmacological management of new-onset epilepsy in adults. 2006;12(1):55-60.

- The cost of treating seizure patients in a managed care organization. 1999;5(4):351-56.

\section{Pharmaceutical Industry and Marketing}

- Assessment of the opportunities for pharmaceutical manufacturers in emerging markets. 2009;15(5):396-402.

- Reapplication requirements for prescription assistance program mischaracterized. [letter and author response] 2007;13(8):687-88.

- Pharmaceutical patient assistance programs: don't look a gift horse in the mouth or there's no such thing as a free lunch. [commentary] 2007;13(7):614-16.

- Pharmaceutical manufacturer prescription assistance programs: are they worth it? [commentary] 2007;13(7):611-13.

- Costs to physician offices of providing medications to medically indigent patients via pharmaceutical manufacturer prescription assistance programs. 2007;13(6):506-14.

- Who needs XR, LA, SR, XL, ER, or CR? [editorial] 2005;11(9):772-73.

- Product-line extensions and pricing strategies of brand-name drugs facing patent expiration. 2005;11(9):746-54.

- India's pharmaceutical industry: a growing influential force in the world pharmaceutical market. 2002;8(3):211-15.

- International movement of Japan's pharmaceutical industry: reform of Japanese health policies, Part III. 1998;4(6):567-68, 571-72, 555-57, 580, 582-83.

- International movement of Japan's pharmaceutical industry: reform of Japanese health policy, Part II. 1998;4(2):123-24, 127-28, 130, 135-37.

- International movement of Japan's pharmaceutical industry: health policy reform. 1997;3(6):667-68, 671-74.

- The drug approval process in the U.S., Europe, and Japan. 1997;3(4):459-65

- Pharmaceutical privatization and reform program in Kazakhstan. 1997;3(4):415-16, 418-19, 422.

- U.S. pharmaceutical firm prospects within the People's Republic of China. 1996;2(3):240-42, 245-48.

- Manufacturer-provided alliances: case studies of the nature of and prospects for several model arrangements. 1996;2(3):227, 231, 235-36, 239.

- Industry partnerships: disease management programs flourish. 1995;1(3):164, 166, 170-72.

- Evaluating the pharmaceutical industry interface with managed care. 1995;1(1):35-39.

\section{Pharmaceutical Pricing, Rebates and Pharmacy Reimbursement}

- What is the price benchmark to replace average wholesale price (AWP)? 2010;16(7):492-501

- AMCP guide to pharmaceutical payment methods, 2009 update (version 2.0). [supplement] 2009;15(6-a):S1-S61.

- AMCP guide to pharmaceutical payment methods. [supplement] 2007;13(8, S-c):S1-S40.
- How much "spread" in AWP pricing is unlawful? [commentary] 2007;13(6):515-16.

- Contractual incentives - a threat to evidence-based medicine? [letter] 2005;11(4):358.

- The relative value of disease management programs versus drug manufacturer rebates. [editorial] 2003;9(6):573.

- Pressure on pharmacy benefit managers for disclosure and demonstration of value-rebates and drug benefit cost savings. [editorial] 2003;9(4):369-71.

- Bargaining between community pharmacies and third-party payers: influences on bargaining outcomes. 2001;7(1):43-49.

- The pharmacy audit: what is it and are you prepared? 1999;5(2):93-94, 98.

\section{Pharmacogenomics}

- Challenges and opportunities in pharmacogenomics and therapeutics. [commentary] 2007;13(7):607-08.

- Implications of pharmacogenomics in the current and future treatment of asthma. 2007;13(6):497-505.

- Drug therapy customized to individual patients. 2002;8(4):296-97.

- Evaluating the potential impact of pharmacogenomics on ADRs. 2002;8(4):285-90.

- Health care professionals' perceptions of the role of pharmacogenomic data. 2002;8(4):278-84.

\section{Pharmacy Education}

- Need for coursework in pharmacy curricula on managed care pharmacy. [letter] 2010;16(6):427.

- Pharmacy students' views of managed care pharmacy and PBMs: should there be more exposure to managed care in the pharmacy curriculum? 2010;16(5):346-54.

- Development of a hospital pharmacy medication safety fellowship. [letter] 2009;15(4):359-61.

- The Society of Industrial Pharmacy Students: a new organization at the University of Houston. [letter] 2003;9(4):372-73.

- Managed care and the University of Texas College of Pharmacy. 2001;7(6):490

- University of Michigan College of Pharmacy and managed care partner to enhance drug therapy. 2001;7(5):345-46.

- An inside look at the benefits of a student pharmacy and therapeutics (P\&T) committee competition from the University of Illinois at Chicago. 2001;7(4):259-60

- Managed care concepts prominently featured in innovative management programs at Duquesne University. 2001;7(2):94, 96.

- Managed care teaching and research in South Dakota. 2001;7(1):10, 11

- Synergy between the University of Louisiana at Monroe and the Louisiana Drug Utilization Review Board. 2000;6(5):420.

- Virginia Commonwealth initiates combined graduate programs. 2000;6(4):327-28.

- College offers certified managed care pharmacist program. 2000;6(3):262-63.

- The University of Maryland's Center on Drugs and Public Policy. 2000;6(2):184-85.

- Teaching managed care pharmacy and disease management in Canada. Evaluation of online prospective DUR programs in community pharmacy practice. 2000;6(1):71-72.

- Managed care pharmacy practice at the Texas Tech University Health Sciences Center School of Pharmacy. 1999;5(6):556-57.

- Description of a formal affiliation between a school of pharmacy and a managed care organization. 1999;5(5):433-37.

- Students gain exposure to managed care principles at a new school of pharmacy. 1999;5(4):371. 
- Improving efficiency and effectiveness in managed care: ongoing efforts at the University of New Mexico College of Pharmacy.

1999;5(2):111

- Cooperative learning in a required outcomes assessment course. 1998;4(4):431-32.

- First managed care pharmacy course at the University of Illinois at Chicago. 1998;4(1):80-81.

- Draft criteria for residency programs in managed care pharmacy. 1997;3(3):363-64, 366, 368, 371.

- Internship takes classroom into the "real world." 1997;3(2):234, 241.

- New degree program at Ole Miss: B.S. in pharmaceutical sciences/ management major. 1997;3(1):112-113.

- Linking the ivory tower and real-world practice: building a synergy bridge in managed care pharmacy. 1997;3(1):107-08, 110.

- Pharmacy internship offers real-world exposure to managed care pharmacy practice. 1998;4(6):605-06.

- Managed care pharmacy at the St. Louis College of Pharmacy. $1996 ; 2(4): 439,442$.

- Managed care pharmacy curriculum in pharmacy schools: the Samford University perspective. 1996;2(3):320.

- Managed care pharmacy education at the University of Washington School of Pharmacy. 1996;2(3):319-20.

- Managed care pharmacy education at MCP. 1996;2(1):53.

\section{Pharmacy Manpower and Job Satisfaction}

- Scope of pharmacy practice: roles, responsibilities, and functions of pharmacists and pharmacy technicians. [letter] 2010;16(77):507-08.

- A closer look at pharmacy technicians. 2003;9(1):84.

- 2002 White Paper on Pharmacy Technicians: needed changes can no longer wait. 2003;9(1):72-83.

- How many pharmacists are in our future? The Bureau of Health Professions projects supply to 2020. 2000;6(6):474-82.

- Charting the demand for pharmacists in the managed care era. 1999;5(4):324-28

- Burnout in a sample of HMO pharmacists using the Maslach Burnout Inventory. 1998;4(5):495-503.

\section{Physician Education Interventions Including Academic Detailing}

- Assessment of eptifibatide dosing in renal impairment before and after in-service education provided by pharmacists. 2007;13(7):598-606

- Effects of physician report cards, knowledge of drug prices, and financial incentives in prescription drug costs. [editorial] 2003;9(4):368.

- Physician education-intervention influenced prescribing for otitis media. 2002;8(2):141-45.

- Selection bias in physician education-intervention programs 2002;8(2):82.

- Effect of physician profiles and academic detailing on cost and utilization of selective serotonin reuptake inhibitors.

2002;8(1):23-31.

- Driving market share in an integrated health system without therapeutic interchange. 2001;7(4):283-86.

- Effect of provider education and feedback on antihypertensive prescribing in a department of Veterans Affairs primary care clinic. 2000;6(4):307-10

- Academic detailing to influence prescribing. 1997;3(6):631-33, 637-38.

- Academic detailing: methods and success stories in IPA-model HMOs. 1996;2(5):586-88, 593-94, 596

- Effectiveness of academic detailing in the managed care environment: improving prescribing of lipid-lowering agents. 1996;2(2):148-57.

- Academic detailing: what's in a name? 1996;2(2):88-90.
- UIC students mobilize first student chapter of AMCP. 1995;1(3):185-86.

\section{Population Health-Interventions and Prevention of ADEs}

- Suboptimal pneumococcal pneumonia vaccination rates among patients at risk in a managed care organization in Israel 2006;12(3):152-56.

- Who bears responsibility for glucocorticoid-exposed patients in a large health maintenance organization? 2001;7(3):228-32.

- An employee influenza initiative in a large university managed care setting. 2001;7(3):219-23.

- Public health, managed care, and pharmacy: an evolving trifecta. 2001;7(1):12, 14-16.

\section{Privacy of Health Information}

- HIPAA effects on health research and PBM functions in drug utilization review. 2003;9(1):95-97.

- The Health Insurance Portability and Accountability Act of 1996 (HIPAA) and the pharmacy benefit: implications for health plans, PBMs, and providers. 2003;9(1):66-71.

- Privacy just took on a whole new meaning: what HIPAA means to pharmacists. 2001;7(5):342.

- Employer access to employee prescription records: dilemmas for pharmacists. 1997;3(5):504-05, 508

\section{Psoriasis}

- Formulary review of 2 new biologic agents: tocilizumab for rheumatoid arthritis and ustekinumab for plaque psoriasis. 2010;16(6):402-16.

- Clinical monograph for drug formulary review: systemic agents for psoriasis/psoriatic arthritis. 2005;11(1):33-55.

- Advancements in the treatment of psoriasis: role of biologic agents. 2004;10(4):318-25.

- Meeting the challenge of incorporating injectable biologics into managed care: multiple sclerosis and psoriasis. [supplement] 2004;10(3, S-b):S1-S45.

\section{Quality Assurance}

- Credentialing in pharmacy. 2001;7(1):22-27, 30-31.

\section{Research Methods and Statistical Analysis} (see also Survey Methods)

- It depends on what "mean" means: averaging versus event patterning in analyses of administrative claims data. [editorial] 2010;16(4):288-91.

- Interpreting hazards: the increasing importance of "antidote to anecdote" in managed care. [editorial] 2010;16(2):134-40.

- Differentiating effective data mining from fishing, trapping, and cruelty to numbers. [editorial] 2007;13(6):517-27.

- Peeking inside the statistical black box: how to analyze quantitative information and get it right the first time. [editorial] 2007;13(1):70-74.

- Appropriate economic methods for pharmacoeconomic studies of retrospective claims data: an introductory guide. [editorial] 2005;11(4):344-48.

- Regression methods in the empiric analysis of health care data. 2005;11(3):240-51.

- Single-patient trial (SPT) method-substitute for expert opinion? [editorial] 2002;8(6):519.

- Statistical significance versus practical significance. [editorial] 2002;8(5):404

- Conjoint analysis in pharmaceutical research. 2002;8(3):206-08.

- Researching managed care pharmacy using Internet searches. 2001;7(3):201-04, 213. 
- Research methodology: designing a research study. 1998;4(5):504-14

- Research methodology: hypotheses, measurement, reliability, and validity. 1998;4(4):382-88.

- The vital role of pharmacy benefit management firms in health services research. 1998;4(1):23-24, 26-28

- Calculating risks and number-needed-to-treat: a method of data interpretation. 1997;3(2):179-83.

- Method is everything: evaluating results by study design. 1997;3(1):66-68, 71-72, 75-76.

- Epidemiological techniques. 1997;3(1):30-32, 35.

- Research methodology: some statistical considerations. 1998;4(6):617-21.

- Measuring quality of life: a primer for managed care pharmacists. 1996;2(4):415-22

- Interface between pharmacoepidemiology and pharmacoeconomics in managed care pharmacy. 1996;2(3):282-89.

- Research in managed care: outcomes research in disease prevention and management. 1996;2(3):212, 214, 216, 221-22.

- Outcomes research, pharmacoeconomics, and the pharmaceutical industry. 1996;2(1):48-52.

- Drug-related morbidity and mortality: a cost-of-illness model. 1996;2(1):39-47.

\section{Safety-Health Care Worker}

- New standards to prevent needle-stick injury. 2001;7(5):349-52.

\section{Safety-Patient Care (see Drug Utilization Review [DUR])}

\section{Specialty Pharmacy}

- Association of prescription abandonment with cost share for highcost specialty pharmacy medications. 2009;15(8):648-58.

- Blurring the lines of medical and pharmacy management: the new role of specialty pharmaceuticals. [supplement] 2008;14(4, S):S1-S25.

- Specialty pharmacy cost management strategies of private health care payers. 2006;12(9):736-44.

- The emergence of specialty pharmacy. 2000;6(4):280-84

\section{Survey Methods}

(see also Research Methods)

- Constructing mail survey questionnaires to maximize the rates of return and assure the validity and reliability of responses. 2002;8(3):225-31.

- Implementing mail survey questionnaires. 2002;8(2):157-61.

- Going to the source: a guide to using surveys in health care research. $1999 ; 5(2): 150-59$

\section{Technology-Automation, Education and Information}

- Evaluation of personal digital assistant drug information databases for the managed care pharmacist. 2003;9(5):441-48

- Use of technology throughout the curriculum. 2002;8(2):86

- Critical evaluation of web sites: an example in osteoporosis. 2000;6(4):316-22

- Adopting knowledge technology to "manage" care: issues and status of physician use. Evaluation of online prospective DUR programs in community pharmacy practice. 2000;6(1):35-41.

- The Internet: changing the managed pharmaceutical care environment. 1999;5(5):387-88, 390, 392.

- The year 2000 in pharmacy-business as usual or disaster in progress? 1999;5(4):305, 308-10.
- Technology and automation update. 1998;4(3):345-50.

- Gaining links: health information networks arise with integration challenges. 1995;1(2):96-98, 100.

- Automated dispensing technologies: effect on managed care. 1995; 1(2):121-27.

- Automation aids prescription processing-but professional judgment remains indispensable. 1995;1(2):90, 93-95.

Therapeutic Interchange-Therapeutic Selection (see also Formulary Management, and Drug Benefit Design)

- Utilization of pharmacy claims data to evaluate therapeutic interchange programs. 1999;5(4):331-34.

- Risk-taking propensity and drug product selection behavior of pharmacists. 1997;3(4):439-43.

\section{Thrombosis, DVT, and VTE}

- Direct medical costs of venous thromboembolism and subsequent hospital readmission rates: an administrative claims analysis from 30 managed care organizations. 2007;13(6):475-86.

- A pilot study of home treatment of deep vein thrombosis with subcutaneous once-daily enoxaparin plus warfarin. 2006;12(1):70-75.

- Effect of a clinical pharmacy education program on improvement in the quantity and quality of venous thromboembolism prophylaxis for medically ill patients. 2005;11(9):755-62

- In search of safe and effective oral anticoagulation. [editorial] 2005;11(8):704-08.

- Longitudinal evaluation of health plan cost per venous thromboembolism or bleed event in patients with a prior venous thromboembolism event during hospitalization. 2005;11(8):663-73.

- Quality improvement in the continuum of care: impact of atherothrombosis in managed care pharmacy. [supplement] 2004;10(6, S-a):S1-S16

- Outpatient treatment of uncomplicated deep vein thrombosis: an overview of program development. 1997;3(2):170, 173-74.

\section{Ulcerative Colitis}

- Administrative claims analysis of all-cause annual costs of care and resource utilization by age category for ulcerative colitis patients. 2008;14(4):352-62.

- The challenge of compliance and persistence: focus on ulcerative colitis. [supplement] 2008;14(1, S-a):S1-S16.

- Mild-to-moderate ulcerative colitis: your role in patient compliance and health care costs. [supplement] 2007;13(7, S-a):S1-S16.

\section{Value of Pharmacotherapy}

- RxHealthValue offers three recommendations and cost research. 2001;7(1):17-20.

\section{Women's Health}

- Preventive care programs to improve the management of perimenopausal and postmenopausal women: guidance for managed care organizations. [supplement] 2008;14(3, S):S1-S22.

- Actuarial analysis of private payer administrative claims data for women with endometriosis. 2007:13(3):262-72.

- Women's health: issues and opportunities for managed care pharmacy. 2001;7(4):263-67.

- Estimating the relative cost effectiveness of four contraceptive methods in the prevention of unwanted pregnancies within the Department of Defense active-duty women. 1999;5(2):131-36. 